\title{
A Combined Patch-Clamp and Electrorotation Study of the Voltage- and Frequency-Dependent Membrane Capacitance Caused by Structurally Dissimilar Lipophilic Anions
}

\author{
D. Zimmermann $\cdot$ M. Kiesel $\cdot$ U. Terpitz $\cdot$ A. Zhou $\cdot$ \\ R. Reuss · J. Kraus • W. A. Schenk • E. Bamberg • \\ V. L. Sukhorukov
}

Received: 23 October 2007/Accepted: 13 December 2007/Published online: 16 January 2008

(C) Springer Science+Business Media, LLC 2007

\begin{abstract}
Interactions of structurally dissimilar anionic compounds with the plasma membrane of HEK293 cells were analyzed by patch clamp and electrorotation. The combined approach provides complementary information on the lipophilicity, preferential affinity of the anions to the inner/outer membrane leaflet, adsorption depth and transmembrane mobility. The anionic species studied here included the well-known lipophilic anions dipicrylamine $\left(\mathrm{DPA}^{-}\right)$, tetraphenylborate $\left(\mathrm{TPB}^{-}\right)$and $\left[\mathrm{W}_{2}(\mathrm{CO})_{10}\left(\mathrm{~S}_{2} \mathrm{CH}\right)\right]^{-}$, the putative lipophilic anion $\mathrm{B}\left(\mathrm{CF}_{3}\right)_{4}^{-}$ and three new heterocyclic $\mathrm{W}(\mathrm{CO})_{5}$ derivatives. All tested anions partitioned strongly into the cell membrane, as indicated by the capacitance increase in patch-clamped cells. The capacitance increment exhibited a bell-shaped dependence on membrane voltage. The midpoint potentials of the maximum capacitance increment were negative, indicating the exclusion of lipophilic anions from the outer membrane leaflet. The adsorption depth of the large organic
\end{abstract}

D. Zimmermann · U. Terpitz · A. Zhou · J. Kraus · E. Bamberg Department of Biophysical Chemistry,

Max-Planck Institute of Biophysics, Max-von-Laue Strasse 3,

D-60438 Frankfurt am Main, Germany

D. Zimmermann $\cdot$ E. Bamberg

Department of Biophysical Chemistry, Chemistry and Pharmacy,

Johann-Wolfgang-Goethe University, Max-von-Laue Strasse 4,

D-60438 Frankfurt am Main, Germany

M. Kiesel · R. Reuss · J. Kraus · V. L. Sukhorukov ( $\bowtie)$ Department of Biotechnology, University of Würzburg, Biozentrum, Am Hubland, D-97074 Würzburg, Germany e-mail: sukhorukov@biozentrum.uni-wuerzburg.de

W. A. Schenk

Institute of Inorganic Chemistry, University of Würzburg, Am Hubland, D-97074 Würzburg, Germany anions $\mathrm{DPA}^{-}, \mathrm{TPB}^{-}$and $\mathrm{B}\left(\mathrm{CF}_{3}\right)_{4}^{-}$increased and that of $\mathrm{W}(\mathrm{CO})_{5}$ derivatives decreased with increasing concentration of mobile charges. In agreement with the patch-clamp data, electrorotation of cells treated with $\mathrm{DPA}^{-}$and $\mathrm{W}(\mathrm{CO})_{5}$ derivatives revealed a large dispersion of membrane capacitance in the kilohertz to megahertz range due to the translocation of mobile charges. In contrast, in the presence of $\mathrm{TPB}^{-}$and $\mathrm{B}\left(\mathrm{CF}_{3}\right)_{4}^{-}$no mobile charges could be detected by electrorotation, despite their strong membrane adsorption. Our data suggest that the presence of oxygen atoms in the outer molecular shell is an important factor for the fast translocation ability of lipophilic anions.

Keywords Hydrophobic ion - Tungsten pentacarbonyl · HEK293 cell · Jurkat cell · Dipicrylamine ·

Tetraphenylborate

\section{Introduction}

Lipophilic ions such as dipicrylamine $\left(\mathrm{DPA}^{-}\right)$, tetraphenylborate $\left(\mathrm{TPB}^{-}\right)$and tetraphenylphosphonium $\left(\mathrm{TPP}^{+}\right)$have been extensively used in biophysical studies as field-sensitive molecular probes which yield information about the structural and physicochemical properties of biological and artificial lipid membranes (Benz, 1988; Oberhauser \& Fernandez, 1995; Lu et al., 1995; Wu \& Santos-Sacchi, 1998; Schamberger \& Clarke, 2002). Unlike most other charged molecules, lipophilic ions readily permeate biological membranes and introduce substantial intrinsic mobile charges within the lipid bilayer, which in turn influence both carrier-assisted and channel-mediated membrane transport (Läuger et al., 1981; Klodos, 2003; Blunck, Chanda \& Bezanilla, 2005). Recently, a number of structurally dissimilar lipophilic anions have been found to 
be very potent inhibitors of volume-sensitive ion channels in mammalian cell membranes (Sukhorukov et al., 2005).

In addition to the well-known $\mathrm{DPA}^{-}$and $\mathrm{TPB}^{-}$, several new classes of lipid-soluble anions with a variety of applications have been identified in recent years. Among others, a number of lipophilic tungsten pentacarbonyl anions, such as $\left[\mathrm{W}(\mathrm{CO})_{5}\left(\mathrm{SC}_{6} \mathrm{H}_{5}\right)\right]^{-},\left[\mathrm{W}_{2}(\mathrm{CO})_{10}\left(\mathrm{~S}_{2} \mathrm{CH}\right)\right]^{-}$ $\left(\mathrm{WW}^{-}\right)$and their analogues, have been proved to be valuable molecular probes for membrane structure and transport studies in living cells (Kürschner et al., 1998; Sukhorukov et al., 2001a). In contrast to the generally toxic derivatives of $\mathrm{TPB}^{-}$and other large organic anions (Arnold et al., 1988), most anionic derivatives of $\mathrm{W}(\mathrm{CO})_{5}$ exhibit fairly low toxicity in mammalian cells, allowing their use not only in biophysical studies but also in biotechnology, particularly for electromanipulation of cells. It is noteworthy that doping cell membranes with tungsten carbonyl anions improves significantly the electrotransfection efficiency of mammalian cells by preventing electrolyte leakage from the cytosol and stabilizing cell volume (Sukhorukov et al., 2005). A further advantage of this particular class of lipophilic anions is that the modular molecular design allows stepwise variation in charge, size, shape, degree of fluorination and chemical functions available for further derivatization (Kürschner et al., 2000; Reuss et al., 2002; Dilsky \& Schenk, 2006).

Until now the interaction of tungsten pentacarbonyls with cell membranes has been studied exclusively by means of AC electrokinetic techniques including electrorotation (ROT) and dielectrophoresis (Kürschner et al., 1998; Reuss et al., 2002). Cells treated with micromolar concentrations of $\mathrm{W}(\mathrm{CO})_{5}$ derivatives exhibit an additional peak in their ROT spectra (i.e., in the frequency dependence of ROT speed) due to a strong dielectric dispersion of the plasma membrane capacitance. This dispersion results from the $\mathrm{AC}$ field-mediated translocation of the adsorbed lipophilic anions between two membrane boundaries accompanied by a marked (some 10-fold) capacitance increment $\left(\Delta C_{\mathrm{LI}}\right)$ at low frequencies. From the ROT spectra, the amount of mobile charges and their translocation rate constants $\left(k_{\mathrm{i}}\right)$ across the plasma membrane can be evaluated by applying an appropriate dielectric model (Sukhorukov \& Zimmermann, 1996; Sukhorukov et al., 2001b).

Despite extensive AC electrokinetic studies, little is known about the relationships between the molecular structure of lipophilic ions and their binding and transport kinetics in cell membranes. This in part can be explained by the experimental limitations of the ROT technique, which suffers from the inability to resolve slow charge relaxations in cell membranes. Since the low frequency limit of ROT is about $100 \mathrm{~Hz}$, this method is only useful for the detection of relatively fast mobile charges (with $k_{\mathrm{i}}>\sim 10^{3} \mathrm{~s}^{-1}$ ), giving rise to a membrane dispersion in the kilohertz to megahertz frequency range. Examples of slow mobile charges are $\mathrm{TPB}^{-}$and $\mathrm{TPP}^{+}$, which exhibit $k_{\mathrm{i}}$ values of $\sim 10 \mathrm{~s}^{-1}$ and $10^{-2}-10^{-3} \mathrm{~s}^{-1}$, respectively, as shown in earlier studies on artificial lipid bilayers and vesicles (Ketterer, Neumcke \& Läuger, 1971; Benz, Läuger \& Janko, 1976; Flewelling \& Hubbell, 1986).

Electrophysiological methods represent an independent approach to the study of cell membranes doped with lipophilic ions (Lu et al., 1995; Benz \& Nonner, 1981; Fernandez, Taylor \& Bezanilla, 1983; Chanda et al., 2005). Although standard patch-clamp techniques do not allow the determination of fast translocation rates (due to the high impedance of the microelectrodes), these methods can be used to monitor the displacement of slow mobile charges not detectable by ROT. Moreover, voltage-clamp measurements can yield information on the voltage-dependent capacitance induced by lipophilic ions, which in turn can be related to the depth of the adsorption sites of lipophilic anions and their distribution between the inner and outer membrane leaflets.

The aim of the present study was to gain deeper insight into the relationships between the structure and membrane transport properties of lipophilic anions by combining the capabilities of electrophysiological and AC electrokinetic methods. To this end, comparative patch-clamp and ROT measurements were performed on the human cell line HEK293 treated with a wide range of structurally dissimilar anionic compounds, including the well-known lipophilic anions $\mathrm{DPA}^{-}, \mathrm{TPB}^{-}, \mathrm{WW}^{-}$, the putative lipophilic anion $\mathrm{B}\left(\mathrm{CF}_{3}\right)_{4}^{-}$as well as three newly synthesized heterocyclic derivatives of $\mathrm{W}(\mathrm{CO})_{5}$. In addition to HEK293 cells, effects of these compounds on human lymphocytes (Jurkat line) and on Xenopus oocytes were examined by means of ROT and the two-electrode voltageclamp (TEVC) technique, respectively.

\section{Materials and Methods}

Chemicals and Synthesis of the Tungsten

Pentacarbonyl Complex Salts

The starting materials for the synthesis of the new tungsten pentacarbonyl complexes $\mathrm{WO}^{-}, \mathrm{WN}^{-}$and $\mathrm{WS}^{-}$(Fig. 1), including 2-mercaptobenzoxazole, 2-mercaptobenzimidazole and 2-mercaptobenzothiazole, were obtained from Sigma-Aldrich (Taufkirchen, Germany). The tungsten complex salts $\mathrm{WO}^{-}, \mathrm{WN}^{-}$and $\mathrm{WS}^{-}$were prepared as follows: $5.5 \mathrm{mmol}$ of the respective heterocycle and subsequently a solution of $\mathrm{Et}_{4} \mathrm{~N}\left(\mathrm{~W}[\mathrm{CO}]_{5} \mathrm{Cl}\right) \quad(2.45 \mathrm{~g}$, $5.0 \mathrm{mmol})$ in tetrahydrofuran $(12 \mathrm{ml})$ were added to a solution of sodium $(0.14 \mathrm{~g}, 6.0 \mathrm{mmol})$ in ethanol $(15 \mathrm{ml})$. 


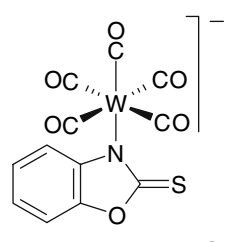

WO-
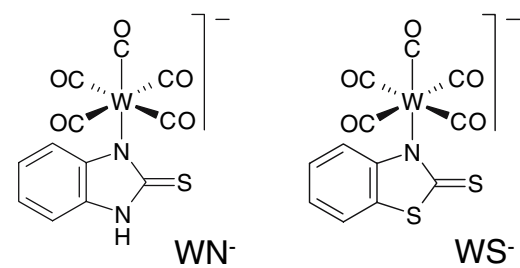

WS-

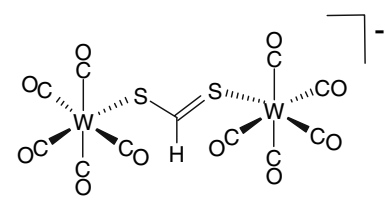

WW-
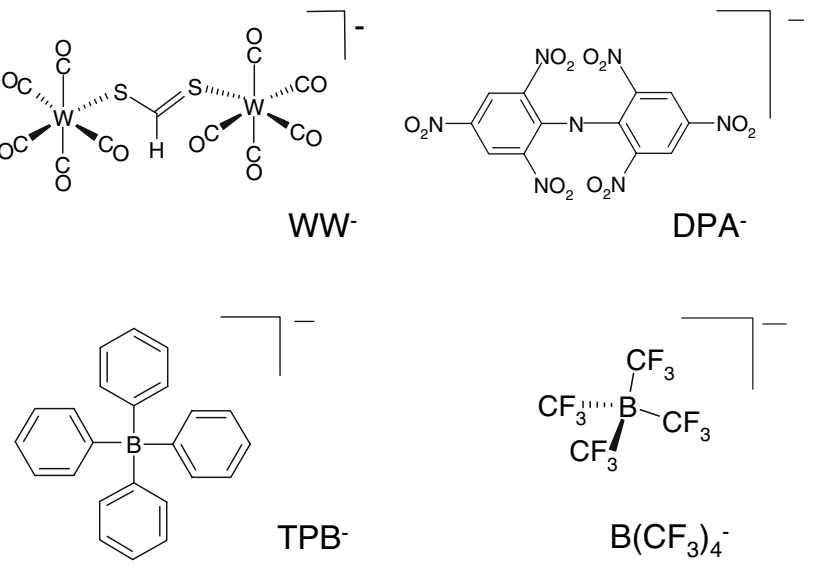

Fig. 1 Structures of the lipophilic anions studied here (notation, salt formula, chemical name): $\mathrm{WO}^{-}, \mathrm{Et}_{4} \mathrm{~N}^{+}\left[\mathrm{W}(\mathrm{CO})_{5}\left(\mathrm{SCNOC}_{6} \mathrm{H}_{4}\right)\right]^{-}$, tetraethylammonium-benzoxazolidin-2-thion-1-yl-pentacarbonyltungstate; $\mathrm{WN}^{-}, \mathrm{Et}_{4} \mathrm{~N}^{+}\left[\mathrm{W}(\mathrm{CO})_{5}\left(\mathrm{SCN}_{2} \mathrm{HC}_{6} \mathrm{H}_{4}\right)\right]^{-}$, tetraethylammonium-benzimidazolidin-2-thion-1-yl-pentacarbonyltungstate; $\mathrm{WS}^{-}, \quad \mathrm{Et}_{4} \mathrm{~N}^{+}$ $\left[\mathrm{W}(\mathrm{CO})_{5}\left(\mathrm{SCNSC}_{6} \mathrm{H}_{4}\right)\right]^{-}, \quad$ tetraethylammonium-benzothiazolidin2-thion-1-yl-pentacarbonyltungstate; $\quad \mathrm{WW}^{-}, \quad \mathrm{Et}_{4} \mathrm{~N}^{+}\left[\mathrm{W}_{2}(\mathrm{CO})_{10}\right.$ $\left.\left(\mu-\mathrm{S}_{2} \mathrm{CH}\right)\right]^{-}$tetraethylammonium decacarbonyl- $\mu$-dithioformiatoditungstate; $\mathrm{DPA}^{-}$, dipicrylamine (2,2',4,4',6,6'-hexanitrodiphenylamine); $\mathrm{TPB}^{-}, \mathrm{Na}^{+}\left[\mathrm{B}\left(\mathrm{C}_{6} \mathrm{H}_{5}\right)_{4}\right]^{-}$sodium tetraphenylborate; $\mathrm{B}\left(\mathrm{CF}_{3}\right)_{4}^{-}$, $\mathrm{Cs}^{+}\left[\mathrm{B}\left(\mathrm{CF}_{3}\right)_{4}\right]^{-}$, cesium tetrakis-(trifluormethyl)-borate

The mixture was stirred for $2 \mathrm{~h}$ at $20^{\circ} \mathrm{C}$ and then vacuumevaporated. The dark brown semisolid residue was dissolved in tetrahydrofuran $(10 \mathrm{ml})$. The solution was filtered through a layer of silica gel and celite. Hexane $(150 \mathrm{ml})$ was added slowly at $0^{\circ} \mathrm{C}$, and the yellow precipitate thus formed was collected by filtration, washed three times with hexane and dried under vacuum (for further details, see also Strohbusch et al., 1979; Abel, Reid \& Butler, 1963).

The synthesis of the tetrabutylammonium salts of $\mathrm{WO}^{-}$, $\mathrm{WN}^{-}$and $\mathrm{WS}^{-}$by a somewhat different route has been recently described by Asali, El-Khateeb \& Battaineh (2003). These authors assumed that the heterocycles are coordinated to the $\mathrm{W}(\mathrm{CO})_{5}$ unit through the sulfur atom. ${ }^{13} \mathrm{C}$ nuclear magnetic resonance (both in solution and in the solid state) and X-ray crystal structure determination of the tetraphenylphosphonium salt of $\mathrm{WO}^{-}$, however, clearly show that the heterocycles are $N$-coordinated in all three cases. Details of this will be the subject of a forthcoming publication.
$\mathrm{WW}^{-}$was synthesized and purified by crystallization as described elsewhere (Kürschner et al., 1998). $\mathrm{DPA}^{-}$was purchased from Dynamit Nobel (Leverkusen, Germany). $\mathrm{CsB}\left(\mathrm{CF}_{3}\right)_{4}$ was kindly provided by Prof. H. Willner (University of Wuppertal, Wuppertal, Germany). The synthesis of the tetrakis(trifluoromethyl)borate anion $\mathrm{B}\left(\mathrm{CF}_{3}\right)_{4}^{-}$and the properties of the salt $\mathrm{CsB}\left(\mathrm{CF}_{3}\right)_{4}$ have been reported elsewhere (Bernhardt et al., 2001).

\section{Xenopus Oocytes}

Breeding of female South African clawed toads (Xenopus laevis), ovariectomy, defolliculation and maintenance of oocytes were performed according to the standard procedures described elsewhere (Nagel et al., 1997). Individual stage V-VI oocytes were obtained from anesthetized frogs and isolated by collagenase treatment using $\mathrm{Ca}^{2+}$-free oocyte Ringer solution ([in mM] $110 \mathrm{NaCl}, 5 \mathrm{KCl}, 1$ $\mathrm{MgCl}_{2}, 5$ 4-[2-hydroxyethyl]-1-piperazineethanesulfonic acid [HEPES]; $\mathrm{pH}$ was adjusted to 7.73 by addition of appropriate amounts of $\mathrm{NaOH}$ ). Single oocytes were stored in an equal solution supplemented with $2 \mathrm{mM} \mathrm{CaCl}_{2}$ and $40 \mathrm{mg} / \mathrm{l}$ gentamycin at $16^{\circ} \mathrm{C}$ for $2-6$ days; solution was changed every 2 days during storing. Prior to measurements, oocytes were transferred to ND96 solution (see below) and kept at $16^{\circ} \mathrm{C}$.

\section{Mammalian Cell Culture}

The human T-lymphocyte cell line Jurkat and the HEK293 human embryonic kidney cell line (hereafter referred to as "HEK" cells) were used in the present study. Jurkat cells were cultured in complete growth medium (CGM) containing RPMI 1640 supplemented with $10 \%$ fetal calf serum (Hyclone, Logan, UT), 2 mm L-glutamine, $100 \mathrm{U} / \mathrm{ml}$ penicillin, $100 \mu \mathrm{g} / \mathrm{ml}$ streptomycin, $2 \mathrm{~mm}$ sodium pyruvate, $1 \times$ minimal essential medium $(\mathrm{MEM})$ nonessential amino acids (PAA, Linz, Austria) and $50 \mu \mathrm{m}$ 2-mercaptoethanol (Sigma, Deisenhofen, Germany). HEK cells were cultured in Dulbecco's MEM (DMEM, PAA) supplemented with $10 \%$ fetal calf serum, $100 \mathrm{U} / \mathrm{ml}$ penicillin and $100 \mu \mathrm{g} / \mathrm{ml}$ streptomycin. Both cell types were cultured at $37^{\circ} \mathrm{C}$ under $5 \% \mathrm{CO}_{2}$. The cultures were split twice or thrice weekly to keep the cells in the exponential growth phase.

\section{Electrophysiological Measurements}

Extracellular solution ND96 used in experiments on oocytes contained (in mM) $96 \mathrm{NaCl}, 2 \mathrm{KCl}, 1.8 \mathrm{CaCl}_{2}, 1.0$ $\mathrm{MgCl}_{2}$ and 5.0 HEPES ( $\mathrm{pH}$ was adjusted to $\mathrm{pH} 7.4$ by 
appropriate addition of $\mathrm{NaOH})$. In patch-clamp experiments on HEK cells the bath solution contained (in mM) $140 \mathrm{NaCl}, 2.0 \mathrm{CaCl}_{2}, 2.0 \mathrm{MgCl}_{2}$ and 10.0 HEPES (pH was adjusted to $\mathrm{pH} 7.4$ by appropriate addition of $\mathrm{NaOH}$ ). Patch pipette solution contained (in mM) $110 \mathrm{KCl}$ or $110 \mathrm{NaCl}$, $2.0 \mathrm{MgCl}_{2}, 10.0$ ethyleneglycoltetraacetic acid (EGTA) and 10.0 HEPES (pH was adjusted to $\mathrm{pH} 7.4$ by appropriate addition of $\mathrm{KOH}$ or $\mathrm{NaOH}$, respectively). The osmolality of the medium was measured using a Semi-MicroOsmometer (Knauer, Berlin-Zehlendorf, Germany). The osmolarities of the media were determined to be 215 mOsm and 250-270 mOsm in the case of oocytes and HEK cells, respectively.

Stock solutions of lipophilic ions were prepared by use of weight balance in dimethyl sulfoxide (DMSO, 25$50 \mathrm{~mm}$ ). In the case of DPA, the concentration of the stock solution in DMSO was $5 \mathrm{~mm}$ as determined photometrically $\left(\varepsilon_{\mathrm{DPA}}=2.3810^{4} \mathrm{M} \cdot \mathrm{cm}^{-1}\right)$. Stock solutions were kept at $4{ }^{\circ} \mathrm{C}$ in the dark. Measuring solutions containing lipophilic ions in the range 5-50 $\mu \mathrm{m}$ were made proximate before their use in an experiment. Solutions containing lipophilic ions were kept in the dark during the time of the experiments.

TEVC measurements were performed on freshly isolated oocytes (1-3 days) at room temperature using a Turbotec05 amplifier (NPI Electronics, Tamm, Germany). Oocytes were subjected to various voltage-clamp protocols in the absence and presence of lipophilic ions. During electrophysiological recording, oocytes were continuously perfused with the corresponding extracellular solution (see above). Micropipettes (GB 150F-8P, $0.86 \times 1.50 \times 80 \mathrm{~mm}$ with filament; Science Products, Hofheim, Germany) with a tip opening of $2-4 \mu \mathrm{m}$ diameter prepared by use of a dual-stage glass micropipette puller (model PC-10; Narishige, London, UK) were filled with a $3 \mathrm{~m} \mathrm{KCl}$ solution. The corresponding pipette resistances measured in extracellular solution (see above) were in the range $0.5-2.5 \mathrm{M} \Omega$.

The patch-clamp setup was installed on a vibrationattenuated table. Current recordings were performed in the whole-cell configuration under voltage-clamp conditions using an Axopatch 200 A voltage-clamp amplifier coupled to a DigiData 1200 interface (Axon Instruments, Union City, CA). Patch-clamp pipettes were fabricated from borosilicate glass capillaries with an internal filament (GC150F-15 or GC150TF-15 glass, external diameter $1.5 \mathrm{~mm}$, wall thickness $0.25 \mathrm{~mm}$; Harvard Apparatus, Holliston, MA). They were pulled on a three-stage horizontal puller (DMZ Universal Puller; Zeitzinstrumente, Martinsried, Germany). Pipettes with a tip diameter of 1$3 \mu \mathrm{m}$ were used for measurements in the whole-cell configuration. The corresponding pipette resistances measured in the bath solution (see above) were in the range 2-4 M $\Omega$.
Liquid junction potentials arising at the external $\mathrm{Ag} /$ $\mathrm{AgCl}$ reference electrode under TEVC and patch-clamp recording conditions were avoided by a salt bridge (containing $1.5 \%$ agarose in $3 \mathrm{~m}$ or $150 \mathrm{~mm} \mathrm{KCl}$ ) between the reference bath (containing $3 \mathrm{M} \mathrm{KCl}$ ) and the measuring chamber. Data were low pass-filtered at 5 or $10 \mathrm{kHz}$ and digitized at a sampling rate of $10-100 \mathrm{kHz}$ using Clampex 8.2 and 9.2 (Axon Laboratories, Union City, CA). For data analysis, the software programs Clampfit 9.2 (Axon Laboratories) and Origin 7.5 (OriginLab, Northampton, MA) were used. All TEVC and patch-clamp experiments were performed at room temperature (about $22^{\circ} \mathrm{C}$ ). For determination of the capacitance in the TEVC and patch-clamp experiments, the cells were subjected to ramp protocols $(\mathrm{dU} / \mathrm{dt}=0.1-2 \mathrm{~V} / \mathrm{s}) \quad$ starting from constant holding potentials between -175 and $+70 \mathrm{~m} V$ (see Fig. 2). The resulting capacitive currents $\left(I_{\mathrm{c}}\right)$ were recorded and analyzed by use of the equation $C_{\mathrm{m}}=I_{\mathrm{C}}(\mathrm{dU} / \mathrm{dt})^{-1}$. Membrane capacitance $\left(C_{\mathrm{m}}\right)$ was in a few cases also determined by analyzing the measured charge movement after application of voltage step protocols.

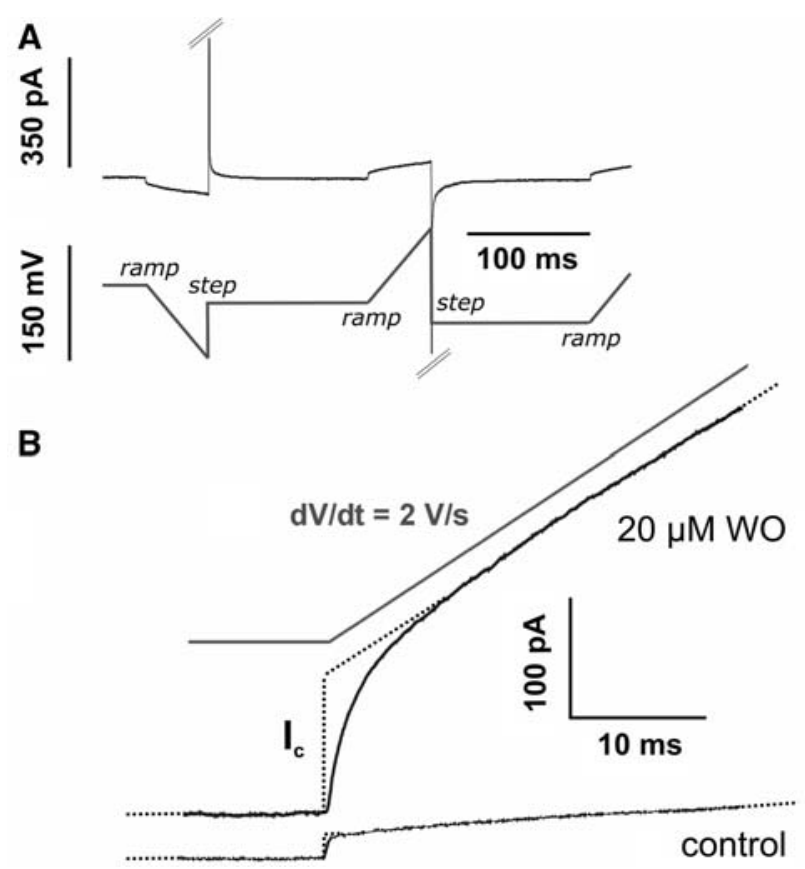

Fig. 2 Patch-clamp measurements on HEK cells in the whole-cell configuration. a A typical voltage protocol applied to a HEK cell and the resulting current recording. Voltage ramps ( $\mathrm{ramp}$ ) are started from different holding potentials. Note that capacitive peak currents resulting after a voltage step (step) are shown only partly. b Current recordings after subjecting a HEK cell to a $+2 \mathrm{~V} / \mathrm{s}$ ramp starting from a holding potential at $-75 \mathrm{mV}$ in the presence and absence of $20 \mu \mathrm{M}$ $\mathrm{WO}^{-}$, respectively. Dotted lines were used to determine the amplitude of corresponding capacitive currents, $I_{\mathrm{c}}$ 


\section{Electrorotation}

Before electrorotation, the cells were washed one or two times with an isosmolar (300 mOsm) sorbitol solution, pelletted and resuspended in either iso- or hyposmolar (100 mOsm) sorbitol solution at a final cell density of 1 to $2 \times 10^{5}$ cells $/ \mathrm{ml}$. Lipophilic ions (Fig. 1) were added to the cell suspension at final concentrations of $1-100 \mu \mathrm{m}$. To reach partition equilibrium for adsorption, the cells were incubated with lipophilic ions for $10-15$ min before electrorotation measurements. The suspension conductivity $\left(\sigma_{\mathrm{e}}\right)$ was adjusted to $5-60 \mathrm{mS} / \mathrm{m}$ by addition of appropriate amounts of HEPES-KOH (pH 7.4). Conductivity and osmolality of the solutions were measured by means of a conductometer (Knick, Berlin, Germany) and a cryoscopic osmometer (Osmomat 030; Gonotec, Berlin, Germany), respectively.

Measurements of the field frequency $\left(f_{\mathrm{c} 1}\right)$ inducing the fastest antifield rotation of cells were performed under lowconductivity conditions $\left(\sigma_{\mathrm{e}}<5 \mathrm{mS} / \mathrm{m}\right)$ by the contrarotating field (CRF) technique using a four-electrode chamber that was described in detail previously (Arnold \& Zimmermann, 1988). ROT spectra were measured in a microstructured four-electrode chamber arranged as a planar array of circular electrodes of $60 \mu \mathrm{m}$ diameter, $140 \mathrm{~nm}$ thickness (20 nm Ta and $120 \mathrm{~nm} \mathrm{Pt}$ ) and $200 \mu \mathrm{m}$ electrode spacing (Sukhorukov et al., 2001a). To produce rotating fields, the adjacent microelectrodes were driven by four $90^{\circ}$ phase-shifted, symmetrical square-wave signals from a pulse generator (HP 8130A; Hewlett-Packard, Boeblingen, Germany) with 2.5-4.8 $\mathrm{V}_{\mathrm{PP}}$ amplitude over the frequency range $100 \mathrm{~Hz}$ to $150 \mathrm{mHz}$.

A sample of cell suspension $(50 \mu \mathrm{l})$ was added to the microstructure, and a coverslip was placed gently over its center. ROT spectra were monitored by decreasing the field frequency in steps (four frequency points per decade). At each field frequency, the rotation speed of an individual cell located near the center of the chamber was determined using a stopwatch. The ROT spectra were normalized to the field strength of $1 \mathrm{~V}_{\mathrm{PP}} / 100 \mu \mathrm{m}$. The cells were observed using a BX 50 microscope (Olympus, Hamburg, Germany) equipped with a charge-coupled device video camera (SSC-M370CE; Sony, Cologne, Germany) connected to a video monitor. Cell radii $(a)$ were determined with a calibrated ocular micrometer.

\section{Results}

\section{Electrophysiology}

Both patch-clamp measurements on HEK cells and TEVC experiments on Xenopus oocytes revealed the capability of all anionic compounds tested in these experiments (including $\mathrm{WO}^{-}, \mathrm{WW}^{-}, \mathrm{DPA}^{-}, \mathrm{TPB}^{-}, \mathrm{B}\left[\mathrm{CF}_{3}\right]_{4}^{-}$) to induce a robust increment of membrane capacitance, $\Delta C_{\mathrm{LI}}$, over the range of holding membrane potentials of -170 to +80 $\mathrm{m} V$ (Figs. 3 and 4). The data points in Figures 3 and 4 are subtractions of the $C_{\mathrm{m}}$ data of untreated controls from $C_{\mathrm{m}}$ data measured in the presence of lipophilic ions. Control $C_{\mathrm{m}}$ values in both HEK cells and oocytes without lipophilic anions were nearly constant over the entire voltage range. The observed capacitance increments $\Delta C_{\mathrm{LI}}$ obviously resulted from the presence of mobile charges in cell membranes of both cell types due to the adsorbed lipophilic anions.

As seen in Figures 3 and 4, the voltage dependence of the induced capacitance changes in HEK cells and Xenopus oocytes was bell-shaped for all lipophilic anions. The magnitude of the capacitance increment, $\Delta C_{\mathrm{LI}}$, increased with increasing anion concentration in extracellular medium. Qualitatively similar voltage-dependent capacitance changes were observed in the presence of 5-50 $\mu \mathrm{m}$ $\mathrm{B}\left(\mathrm{CF}_{3}\right)_{4}^{-}$in both patch-clamped HEK cells (data not shown) and oocytes (Fig. 4).

The measured $\Delta C_{\mathrm{LI}}-V_{\mathrm{H}}$ relations could be approximated very well by the first derivative of the Boltzmann function given by equation 1 (see Appendix). Curve fitting yielded the maximum capacitance increment $\left(\Delta C_{\mathrm{LI}}^{\max }\right)$ at the midpoint potential $\left(V_{\mathrm{mid}}\right)$ and the slope parameter $(\alpha)$. The fitted values of $\Delta C_{\mathrm{LI}}^{\max }, \alpha$ and $V_{\text {mid }}$ for the various lipophilic anions derived for patch-clamped HEK cells and from TEVC experiments on oocytes are summarized in Tables 1 and 2, respectively. The tables also include data for the surface density $\left(N_{\mathrm{t}}, \mathrm{nmol} / \mathrm{m}^{2}\right)$ of the adsorbed lipophilic anions calculated as $\mathrm{N}_{\mathrm{t}}=4 R T \Delta C_{\mathrm{LI}}^{\max } /\left(\alpha F^{2}\right)$ (Fernandez et al., 1983), as well as values of the areaspecific membrane conductance $\left(G_{\mathrm{m}}\right)$ measured at zero holding voltage.

The following trends are evident from the data in Tables 1 and 2. In general, the capacitance increment, $\Delta C_{\mathrm{LI}}^{\max }$, and thus the concentration of adsorbed lipophilic anions, $N_{\mathrm{t}}$, increased with increasing concentration $c$ of lipophilic anions in extracellular medium. Except for HEK cells treated with $5 \mu \mathrm{M} \mathrm{WO}^{-}$(Table 1), the peak capacitance increment was centered at negative (hyperpolarized) membrane potentials $\left(V_{\text {mid }}<0\right)$. Moreover, the midpoint potential, $V_{\text {mid }}$, became more negative with increasing concentration $N_{\mathrm{t}}$ of mobile charges in the cell membrane. In the case of large organic anions $\left(\mathrm{DPA}^{-}, \mathrm{TPB}^{-}\right.$and $\left.\mathrm{B}\left[\mathrm{CF}_{3}\right]_{4}^{-}\right)$, the slope parameter $\alpha$ decreased with increasing $N_{\mathrm{t}}$. In contrast, in the case of anionic derivatives of $\mathrm{W}(\mathrm{CO})_{5}, \quad \alpha$ remained nearly unchanged $\left(\mathrm{WO}^{-}\right)$or increased $\left(\mathrm{WW}^{-}\right)$with increasing $N_{\mathrm{t}}$.

In order to validate the above findings, we further analyzed the interactions of lipophilic compounds with cell 
Fig. 3 Voltage dependence of the area-specific membrane capacitance increment $\left(\Delta C_{\mathrm{LI}}\right)$ induced in HEK cells by the adsorbed lipophilic anions $\mathrm{WO}^{-}$ (a), $\mathrm{WW}^{-}(\mathbf{b}), \mathrm{DPA}^{-}$(c) and $\mathrm{TPB}^{-}$(d). Membrane capacitance was measured by whole-cell patch clamp. The plotted $\Delta C_{\mathrm{LI}}$ data (symbols) were calculated by subtracting the capacitance values of control cells from those of cells treated with various anion concentrations: $5 \mu \mathrm{M}$ (open circles), $20 \mu \mathrm{M}$ (open squares) and $50 \mu \mathrm{M}$ (filled circles). Curves are least-square fits of the first derivative of the Boltzmann function (equation 1). The fitted parameters are summarized in Table 1
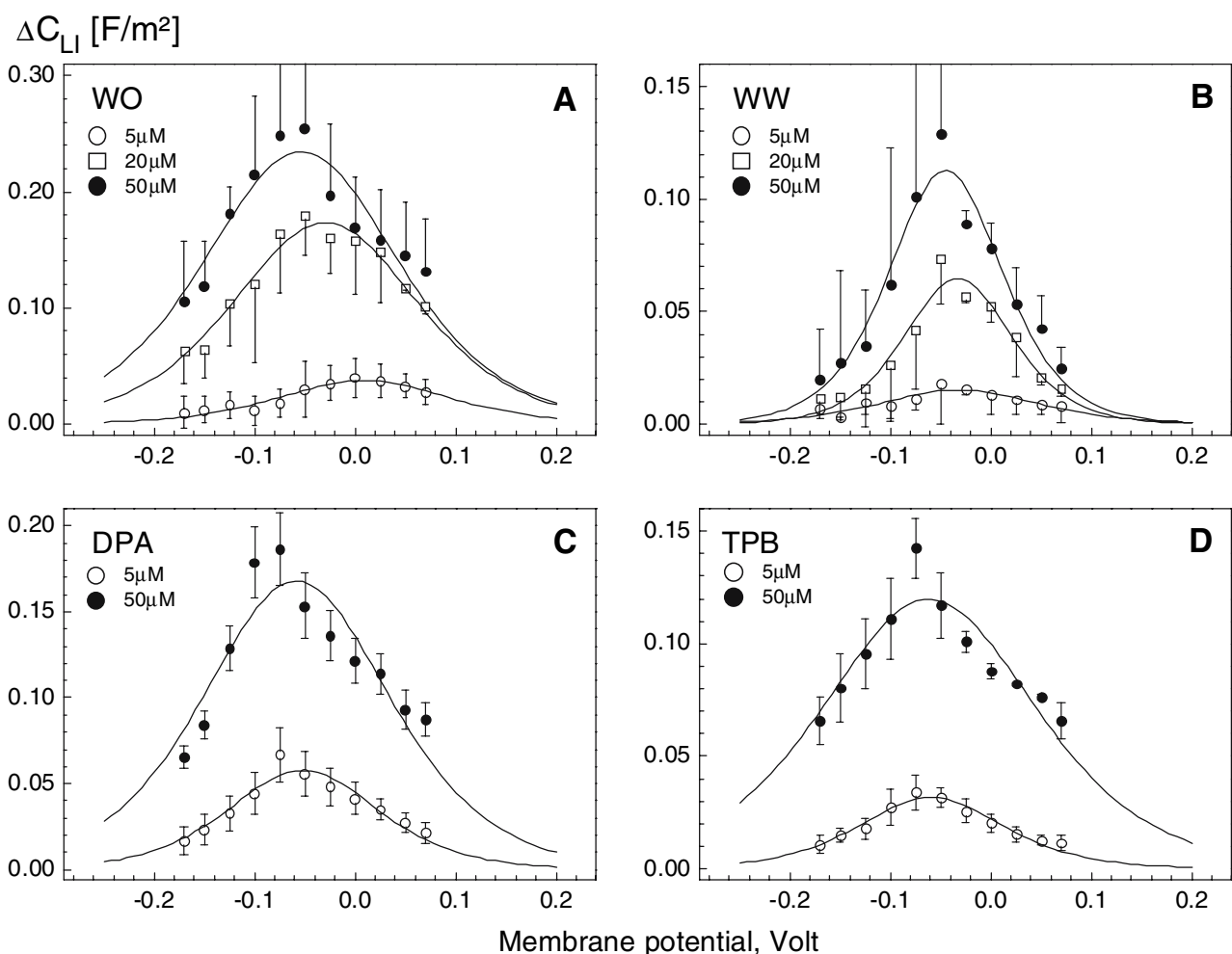

membranes in the frequency domain by means of ROT. Since our ROT setup is not applicable to the large-sized Xenopus oocytes, ROT measurements were performed in parallel on two different human cell lines, HEK cells and Jurkat lymphocytes.

\section{Electrorotation of Control Cells}

The ROT spectrum of untreated Jurkat cells (Fig. 5a, open circles) suspended in $100 \mathrm{mOsm}$ medium exhibited two peaks: an antifield peak (indicated by $f_{\mathrm{c} 1}$ ) centered at $\sim 160 \mathrm{kHz}$ and a cofield peak at $f_{\mathrm{c} 2} \approx 16 \mathrm{MHz}$. The spectrum could be fitted very accurately by the single-shell model (dotted curve), i.e., by a combination of equations 2 and 3 as shown in the Appendix. In agreement with this model, measurements of $f_{\mathrm{c} 1}$ by the CRF technique also revealed a strong linear dependence of the radius-normalized $f_{\mathrm{c} 1}$ value $\left(f_{\mathrm{c} 1} \times a\right)$ on the external conductivity, $\sigma_{\mathrm{e}}$ (Fig. 5b). Linear regression of equation 4 to the $f_{\mathrm{c} 1} \times a$ data of control Jurkat cells gave the following values for area-specific membrane capacitance and conductance: $C_{\mathrm{m}}=7.1 \pm 0.1 \mathrm{mF} / \mathrm{m}^{2} \quad$ and $\quad G_{\mathrm{m}}=90 \pm 20 \mathrm{~S} / \mathrm{m}^{2}$, respectively. Using these data, the permittivity and conductivity of the cytosol were derived from the ROT spectra: $\varepsilon_{\mathrm{i}}=(137 \pm 5) \cdot \varepsilon_{0}$ and $\sigma_{\mathrm{i}}=287 \pm 10 \mathrm{mS} / \mathrm{m}$, respectively. The electrical properties of Jurkat cells are summarized in Table 3.
The ROT spectra of control HEK cells in both isotonic (Fig. 5c) and hypotonic media (not shown) were qualitatively similar to those of Jurkat lymphocytes (Fig. 5a). The analysis of the ROT spectra and CRF data (Fig. 5d) of HEK cells in terms of the single-shell model yielded the plasma membrane and cytosol parameters summarized in Table 3. As evident from the table, reduction of osmolality from 300 to $100 \mathrm{mOsm}$ led to a decrease of $C_{\mathrm{m}}$ from 8.5 to $7.5 \mathrm{mF} / \mathrm{m}^{2}$, suggesting retraction of microvilli and membrane smoothing in hypotonically swollen cells (Kiesel et al., 2006). Apart from the structural changes in the plasma membrane, reduction of osmolality also resulted in an about threefold decrease of the cytosolic conductivity, $\sigma_{\mathrm{i}}$, from 533 to $175 \mathrm{mS} / \mathrm{m}$. This effect can be explained by the dilution of the cytosol due to cell swelling along with the loss of cytosolic ions through swelling-activated channels, as shown recently for Jurkat cells (Kiesel et al., 2006).

\section{Electrorotation of Cells Treated with Lipophilic Anions}

We first analyzed the effects of three newly synthesized heterocyclic derivatives of $\mathrm{W}(\mathrm{CO})_{5}\left(\mathrm{WO}^{-}, \mathrm{WN}^{-}\right.$and $\mathrm{WS}^{-}$) on the ROT spectra of Jurkat and HEK cells. As seen in Figures $5 \mathrm{a}$ and $4 \mathrm{c}$, micromolar concentrations of $\mathrm{WO}^{-}$ altered drastically the low-frequency antifield part of ROT spectra in both cell types, whereas the shape of the high- 


$$
\Delta \mathrm{C}_{\mathrm{LI}}\left[\mathrm{F} / \mathrm{m}^{2}\right]
$$
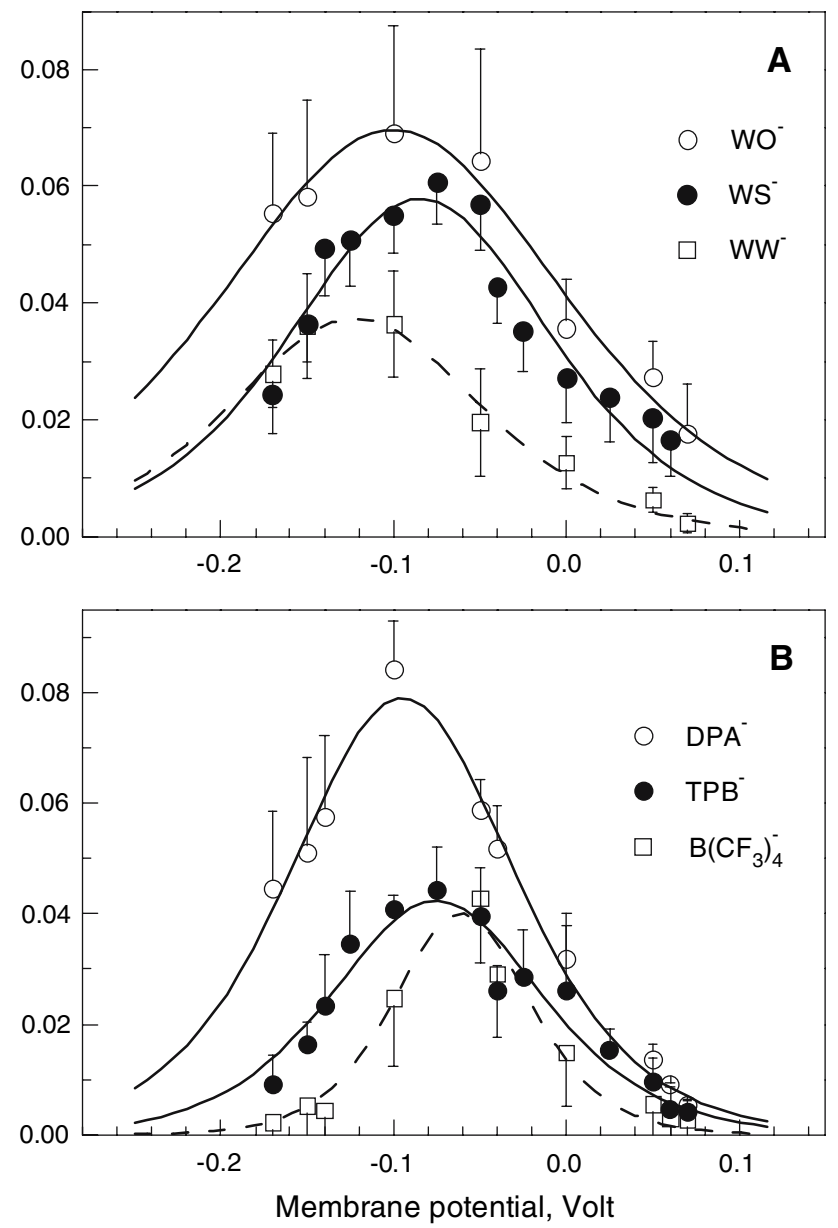

Fig. 4 Voltage dependence of the area-specific membrane capacitance increment $\left(\Delta C_{\mathrm{LI}}\right)$ induced in Xenopus oocytes by the indicated lipophilic anions. Membrane capacitance was measured by the TEVC technique. The plotted $\Delta C_{\mathrm{LI}}$ data (symbols) were calculated by subtracting the capacitance values of control cells from those of treated cells. Curves are least-square fits of the first derivative of the Boltzmann function (equation 1). For further details, see Table 2

frequency cofield peak remained unchanged. In contrast to control lymphocytes exhibiting a single antifield peak (Fig. 5a, open circles), the spectra of cells treated with $20 \mu \mathrm{M} \mathrm{WO}^{-}$displayed an additional antifield peak at about $32 \mathrm{kHz}$ (Fig. 5a, filled circles). In these spectra, the three peaks centered at the characteristic frequencies $f_{\mathrm{LI}}, f_{\mathrm{c} 1}$ and $f_{\mathrm{c} 2}$ are dominated by the relaxation of the adsorbed lipophilic ions (mobile charges), capacitive membrane charging and polarization of the cytosol, respectively. The magnitude of the mobile charge peak increased with increasing $\mathrm{WO}^{-}$concentration (Fig. 5a, filled squares). $\mathrm{WN}^{-}$affected ROT spectra similarly but to a lesser extent than $\mathrm{WO}^{-}$, suggesting lower amounts of mobile charges in the plasma membrane (spectra not shown). Changes in the ROT spectra of HEK cells treated with various $\mathrm{WO}^{-}$ concentrations (Fig. 5c, filled symbols) were comparable to the results obtained on Jurkat cells (Fig. 5a).

Despite its similar structure to $\mathrm{WO}^{-}$and $\mathrm{WN}^{-}$, compound $\mathrm{WS}^{-}$was found to exert notable toxic effects on both Jurkat and HEK cells. Thus, unlike $\mathrm{WO}^{-}, \mathrm{WN}^{-}$and $\mathrm{WW}^{-}$, which did not cause any damage to cells at concentrations up to $50 \mu \mathrm{m}$, the addition of $10-20 \mu \mathrm{M} \mathrm{WS}^{-}$ resulted in progressive granulation of the cytoplasm and cell lysis within a few minutes. For this reason, ROT measurements could be performed only in the presence of $5 \mu \mathrm{M} \mathrm{WS}{ }^{-}$. At this concentration, however, $\mathrm{WS}^{-}$did not affect significantly the ROT spectra of both cell types.

In addition to the heterocyclic derivatives of $\mathrm{W}(\mathrm{CO})_{5}^{-}$, we explored the effects of the lipophilic ions $\mathrm{WW}^{-}, \mathrm{DPA}^{-}$ and $\mathrm{TPB}^{-}$as well as of the putative lipophilic anion $\mathrm{B}\left(\mathrm{CF}_{3}\right)_{4}^{-}$on the ROT spectra of the two mammalian cell lines. As expected, at concentrations of 5-50 $\mu \mathrm{M} \mathrm{WW}^{-}$and $\mathrm{DPA}^{-}$substantial mobile charges were incorporated into the plasma membrane of lymphocytes readily detectable by ROT (spectra not shown).

The complex ROT spectra of mammalian cells treated with $\mathrm{WO}^{-}, \mathrm{WN}^{-}, \mathrm{WW}^{-}$and $\mathrm{DPA}^{-}$could very accurately be approximated by the mobile charge model (see Appendix, equations 2, 3 and 5). For calculation of the least-square fits (solid and dashed curves in Fig. 5a, c), we used the corresponding $C_{\mathrm{m}}$ and $G_{\mathrm{m}}$ values obtained by the CRF technique (Fig. 5b,d). Curve fitting yielded values for $\Delta C_{\mathrm{LI}}$ due to the adsorbed lipophilic anions and their translocation rate constants $\left(k_{\mathrm{i}}\right)$ across the plasma membrane, as well as the cytosolic permittivity $\varepsilon_{i} \varepsilon_{0}$ and conductivity $\sigma_{\mathrm{i}}$. The fitted parameters for the lipophilic anions are summarized in Tables 4 (HEK cells) and 5 (Jurkat cells).

In contrast to the effects of $\mathrm{DPA}^{-}$and $\mathrm{W}(\mathrm{CO})_{5}$ derivatives, the ROT spectra of both cell types treated with $\mathrm{TPB}^{-}$or $\mathrm{B}\left(\mathrm{CF}_{3}\right)_{4}^{-}$(at concentrations up to $100 \mu \mathrm{M}$ ) were similar to the corresponding spectra of control cells, despite the strong adsorption of these anions to cell membranes, as proved by the capacitance recordings on HEK cells (Fig. 3) and oocytes (Fig. 4) using the TEVC technique.

\section{Discussion}

Membrane capacitance increments $\left(\Delta C_{\mathrm{LI}}\right)$ resulting from the relaxation of adsorbed lipophilic anions (mobile charges) can be monitored by both ROT and voltage-clamp techniques. Comparing $\Delta C_{\mathrm{LI}}$ measurements in the presence of various concentrations of $\mathrm{WW}^{-}$on HEK cells revealed good agreement between the two methods (Fig. 6a). In the case of $\mathrm{WO}^{-}$, however, $\Delta C_{\mathrm{LI}}$ and, thus, the amounts of mobile charges determined by voltage-clamp exceeded significantly (by a factor of $\sim 5-6$ ) the corresponding data 
Table 1 Effects of lipophilic anions on the plasma membrane capacitance and conductance in patch-clamped HEK293 cells

\begin{tabular}{lccccccc}
\hline Lipophilic anion & Concentration $(\mu \mathrm{M})$ & \multicolumn{1}{c}{$\Delta C_{\mathrm{LI}}^{\max }\left(\mathrm{mF} / \mathrm{m}^{2}\right)$} & $N_{\mathrm{t}}\left(\mathrm{nmol} / \mathrm{m}^{2}\right)$ & $V_{\text {mid }}(\mathrm{m} V)$ & $\alpha$ & $G_{\mathrm{m}}(0 \mathrm{~m} V)\left(\mu \mathrm{S} / \mathrm{cm}^{2}\right)$ & $n$ \\
\hline $\mathrm{WO}^{-}$ & 5 & $37 \pm 3$ & $89 \pm 8$ & $8.6 \pm 7.7$ & $0.45 \pm 0.05$ & $69 \pm 10$ \\
$\mathrm{WO}^{-}$ & 20 & $173 \pm 7$ & $445 \pm 17$ & $-29.6 \pm 3.3$ & $0.41 \pm 0.02$ & $308 \pm 46$ \\
$\mathrm{WO}^{-}$ & 50 & $235 \pm 16$ & $628 \pm 42$ & $-53.5 \pm 3.1$ & $0.40 \pm 0.04$ & $484 \pm 141$ \\
$\mathrm{WW}^{-}$ & 5 & $15 \pm 2$ & $34 \pm 3$ & $-31.7 \pm 7.8$ & $0.47 \pm 0.06$ & $70 \pm 11$ & 3 \\
$\mathrm{WW}^{-}$ & 20 & $64 \pm 4$ & $97 \pm 6$ & $-32.7 \pm 3.9$ & $0.70 \pm 0.06$ & $75 \pm 10$ \\
$\mathrm{WW}^{-}$ & 50 & $113 \pm 7$ & $177 \pm 11$ & $-44.8 \pm 3.9$ & $0.67 \pm 0.05$ & $88 \pm 16$ \\
$\mathrm{DPA}^{-}$ & 5 & $58 \pm 3$ & $121 \pm 7$ & $-51.7 \pm 4.8$ & $0.51 \pm 0.04$ & $219 \pm 18$ \\
$\mathrm{DPA}^{-}$ & 50 & $167 \pm 14$ & $423 \pm 35$ & $-58.2 \pm 7.1$ & $0.41 \pm 0.05$ & $451 \pm 81$ \\
$\mathrm{TPB}^{-}$ & 5 & $32 \pm 2$ & $64 \pm 3$ & $-59.5 \pm 3.7$ & $0.52 \pm 0.03$ & $132 \pm 44$ \\
$\mathrm{TPB}^{-}$ & 50 & $120 \pm 9$ & $353 \pm 27$ & $-61.4 \pm 6.7$ & $0.36 \pm 0.04$ & $327 \pm 42$ \\
$\mathrm{~B}\left(\mathrm{CF}_{3}\right)_{4}^{-}$ & 5 & $29 \pm 2$ & $54 \pm 3.7$ & $-51.1 \pm 5.1$ & $0.56 \pm 0.05$ & $203 \pm 31$ \\
$\mathrm{~B}\left(\mathrm{CF}_{3}\right)_{4}^{-}$ & 50 & $110 \pm 11$ & $313 \pm 30$ & $-56.0 \pm 8.4$ & $0.37 \pm 0.07$ & $240 \pm 54$ \\
\hline
\end{tabular}

Table 2 Effects of lipophilic anions on the plasma membrane capacitance and conductance of Xenopus oocytes

\begin{tabular}{lllrrrrr}
\hline Lipophilic anion & Concentration $(\mu \mathrm{M})$ & $\Delta C_{\mathrm{LI}}^{\max }\left(\mathrm{mF} / \mathrm{m}^{2}\right)$ & $N_{\mathrm{t}}\left(\mathrm{nmol} / \mathrm{m}^{2}\right)$ & $V_{\text {mid }}(\mathrm{m} V)$ & $\alpha$ & $G_{\mathrm{m}}(0 \mathrm{~m} V)\left(\mu \mathrm{S} / \mathrm{cm}^{2}\right)$ & $n$ \\
\hline $\mathrm{WO}^{-}$ & 20 & $70.4 \pm 4.1$ & $190.8 \pm 11.0$ & $-100.2 \pm 5.8$ & $0.39 \pm 0.03$ & $207 \pm 97$ \\
$\mathrm{WW}^{-}$ & 50 & $37.0 \pm 2.7$ & $75.5 \pm 5.5$ & $-122.3 \pm 5.7$ & $0.52 \pm 0.05$ & $169 \pm 73$ \\
$\mathrm{WS}^{-}$ & 20 & $58.4 \pm 3.3$ & $121.0 \pm 6.9$ & $-84.5 \pm 4.2$ & $0.51 \pm 0.04$ & $436 \pm 34$ \\
$\mathrm{DPA}^{-}$ & 50 & $78.4 \pm 2.7$ & $143.0 \pm 5.0$ & $-94.9 \pm 2.4$ & $0.58 \pm 0.03$ & $269 \pm 51$ & 4 \\
$\mathrm{TPB}^{-}$ & 50 & $42.1 \pm 2.5$ & $71.9 \pm 4.3$ & $-75.1 \pm 4.0$ & $0.62 \pm 0.05$ & $117 \pm 28$ \\
$\mathrm{~B}\left(\mathrm{CF}_{3}\right)_{4}^{-}$ & 50 & $40 \pm 2.8$ & $44.2 \pm 3.1$ & $-60.6 \pm 3.7$ & $0.96 \pm 0.09$ & $178 \pm 62$ \\
\hline
\end{tabular}

obtained by electrorotation (Tables 1 and 4). At least two possible explanations are conceivable for the observed discrepancy between $\Delta C_{\mathrm{LI}}$ values. Firstly, the discrepancy can arise from the strong difference in experimental conditions. Whereas patch-clamped cells were exposed to nearly physiological saline solutions, ROT measurements were performed in sugar-substituted media containing only a few $\mu \mathrm{M}$ of electrolyte. Ionic strength can affect the interaction of lipophilic ions with phospholipid membranes via several mechanisms, such as the ionic strength-mediated changes in the surface membrane potential as well as variations in the activity coefficient, solubility and partition behavior of lipophilic ions (Flewelling \& Hubbell, 1986). Secondly, given the bell-shaped voltage dependence of $\Delta C_{\mathrm{LI}}$ (Fig. 3), a further reason for the low $\Delta C_{\mathrm{LI}}$ values detected by ROT may be a depolarization of the cell membrane doped with $\mathrm{WO}^{-}$. The strong increase of membrane conductance $\left(G_{\mathrm{m}}\right)$ observed in $\mathrm{WO}^{-}$-treated HEK cells (Table 1) is consistent with this assumption. As mentioned in the Appendix, the membrane voltage is not controlled during electrorotation measurements. Therefore, the $\Delta C_{\mathrm{LI}}$ value derived from electrorotation spectra can be smaller than the peak values $\left(\Delta C_{\mathrm{LI}}^{\max }\right)$ measured by voltage clamp if the membrane potential diverges significantly from the midpoint potential $\left(V_{\mathrm{mid}}\right)$.
Judging by the $\Delta C_{\mathrm{LI}}$ data, the concentration of mobile charges $N_{\mathrm{t}}$ in the plasma membrane increased with increasing concentration of the lipophilic anions (e.g., data for HEK cells treated with $\mathrm{WW}^{-}$and $\mathrm{WO}^{-}$in Tables 1 and 4). Comparison of the $N_{\mathrm{t}}$ values recorded on patch-clamped HEK cells in the presence of $5 \mu \mathrm{M}$ of lipophilic anions showed that their lipophilicity decreased in the following order: $\mathrm{DPA}^{-}>\mathrm{WO}^{-}>\mathrm{TPB}^{-}>$ $>\mathrm{WW}^{-}$. Unlike the translocation rate (see below), the lipophilicity apparently does not depend on the molecular structure.

Among the various lipophilic anions tested here, only $\mathrm{WS}^{-}$was found to exert notable toxic effects on the two mammalian cell lines studied. The cytotoxicity can presumably be associated with specific chemical interactions of the S-C-S moieties of benzothiazole (the ligand of WS) with membrane and cytosolic proteins. There is a large body of evidence in the literature for a strong cytotoxicity (including antitumor, antibacterial and fungicide activities) of benzothiazole and related compounds (De Wever et al., 1998; Mukherjee et al., 2005; Singh et al., 2006). Compared to the free benzothiazole, the toxic action of the benzothiazole residue in $\mathrm{WS}^{-}$might be even larger due to the strong membrane adsorption of the lipophilic anion $\mathrm{WS}^{-}$. 


\section{$\Omega$, Radian/s}
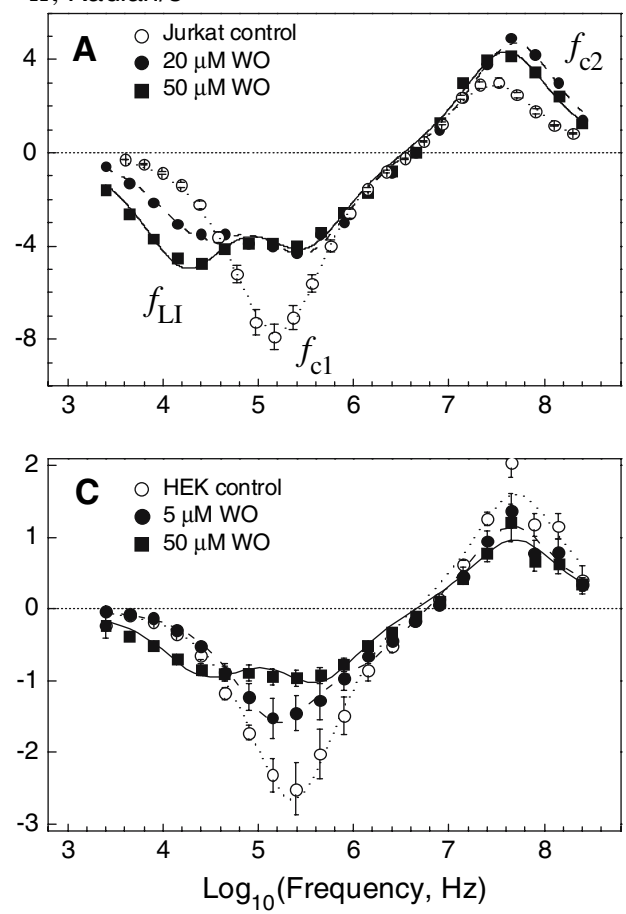

Fig. 5 Analysis of the electric properties of Jurkat $(\mathbf{a}, \mathbf{b})$ and HEK (c, d) cells by electrorotation. a, c The ROT spectra of untreated control cells (open symbols) were fitted by the single-shell model (dotted curves). The radius-normalized $f_{\mathrm{c} 1}$ data of control Jurkat and HEK cells measured by the CRF technique and plotted vs. $\sigma_{\mathrm{e}}$ are shown in b and d, respectively. The lines are calculated by regression of equation 4 to the data points (b $n=320$ cells, $\mathbf{d} n=180$ cells). The fitted $C_{\mathrm{m}}$ and $G_{\mathrm{m}}$ values are summarized in Table 3 . The effects of increasing concentration of $\mathrm{WO}^{-}$on the ROT spectra of Jurkat and
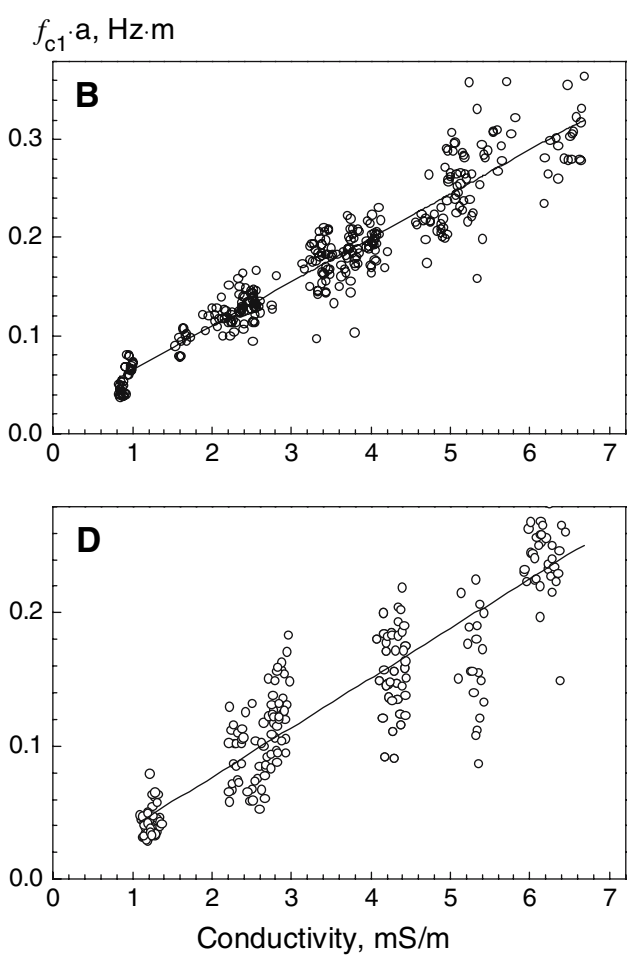

HEK cells are shown in a and $\mathbf{c}$ (filled symbols), respectively. All spectra were measured at $\sigma_{\mathrm{e}} \approx 60 \mathrm{mS} / \mathrm{m}$. The solution osmolalities were $100(\mathbf{a}, \mathbf{b})$ and $300(\mathbf{c}, \mathbf{d}) \mathrm{mOsm} . f_{\mathrm{c} 1}, f_{\mathrm{c} 2}$ and $f_{\mathrm{LI}}$ in a denote the plasma membrane, cytosolic and mobile charge peaks, respectively. Dashed and solid curves in a and $\mathbf{c}$ represent best fits of the mobile charge model (equations 2, 3 and 5) to the ROT spectra of cells treated with $\mathrm{WO}^{-}$. The fitted parameters for HEK and Jurkat cells are given in Tables 4 and 5, respectively

Table 3 Dielectric properties of HEK293 and Jurkat cells measured by electrorotation

\begin{tabular}{llllllcc}
\hline Cell line & Treatment & Medium osmolarity $(\mathrm{mOsm})$ & $C_{\mathrm{m}}\left(\mathrm{mF} / \mathrm{m}^{2}\right)^{\mathrm{a}}$ & $G_{\mathrm{m}}\left(\mathrm{S} / \mathrm{m}^{2}\right)^{\mathrm{a}}$ & $\sigma_{\mathrm{i}}(\mathrm{mS} / \mathrm{m})^{\mathrm{b}}$ & $\varepsilon_{\mathrm{i}} / \varepsilon_{0}$ & ${ }^{\mathrm{b}}$ \\
\hline HEK293 & Control & 300 & $8.5 \pm 0.3$ & $\sim 0$ & $533 \pm 63$ & $71 \pm 9$ & $260(10)$ \\
HEK293 & Control & 100 & $7.5 \pm 0.3$ & $126 \pm 33$ & $175 \pm 14$ & $85 \pm 15$ & $80(23)$ \\
Jurkat & Control & 100 & $7.1 \pm 0.1$ & $90 \pm 20$ & $287 \pm 10$ & $137 \pm 5$ & $316(21)$ \\
\hline
\end{tabular}

${ }^{\text {a }} C_{\mathrm{m}}$ and $G_{\mathrm{m}}$ were determined by the CRF technique.

${ }^{\mathrm{b}} \sigma_{\mathrm{i}}$ and $\varepsilon_{\mathrm{i}}$ were calculated from the ROT spectra; $\varepsilon_{0}=8.8510^{-12} \mathrm{~F} / \mathrm{m}$ is the absolute permittivity of vacuum

Voltage Dependence of the Induced Membrane Capacitance

Independent of the cell type and chemical structure of lipophilic anions, qualitatively similar bell-shaped relationships were found between capacitance increment $\left(\Delta C_{\mathrm{LI}}\right)$ and holding membrane potential $\left(V_{\mathrm{H}}\right)$ (Figs. 3 and 4$)$. The $\Delta C_{\mathrm{LI}}-V_{\mathrm{H}}$ relations exhibited a peak value $\left(\Delta C_{\mathrm{LI}}^{\max }\right)$ centered at a midpoint potential $\left(V_{\mathrm{mid}}\right)$. The magnitude of $\Delta C_{\mathrm{LI}}$ declined rapidly from $\Delta C_{\mathrm{LI}}^{\max }$ to zero as the holding potential was either increased $\left(V_{\mathrm{H}}>V_{\text {mid }}\right)$ or decreased $\left(V_{\mathrm{H}}<V_{\text {mid }}\right)$. The bell-shaped $\Delta C_{\mathrm{LI}}-V_{\mathrm{H}}$ relation most likely originates from the voltage-dependent distribution of the adsorbed lipophilic anion between the two membrane interfaces. At large negative (hyperpolarized) potentials $\left(V_{\mathrm{H}}<<V_{\text {mid }}\right)$, the adsorbed anions are concentrated mainly at the extracellular side of the plasma membrane and vice versa at large positive potentials at the cytosolic side. Under these conditions, no charge displacement across the membrane (and thus no capacitance increment) can occur in response to small-voltage perturbations. By contrast, lipophilic anions distribute equally between the extra- and intracellular membrane sides when the membrane potential is close to $V_{\text {mid. }}$. This distribution pattern enables a voltage-driven 
Table 4 The membrane capacitance increments $\left(\Delta C_{\mathrm{LI}}\right)$, translocation rate constants $\left(k_{\mathrm{i}}\right)$ of mobile charges and cytosolic properties of HEK293 cells $\left(\sigma_{\mathrm{i}}\right.$ and $\left.\varepsilon_{\mathrm{i}}\right)$ derived from the ROT spectra in the presence of various concentrations of lipophilic anions

\begin{tabular}{|c|c|c|c|c|c|c|}
\hline Lipophilic anion & Concentration $(\mu \mathrm{M})$ & $\Delta C_{\mathrm{LI}}\left(\mathrm{mF} / \mathrm{m}^{2}\right)$ & $k_{\mathrm{i}}\left[1 /\left(\mathrm{s} * 10^{3}\right)\right]$ & $\sigma_{\mathrm{i}}(\mathrm{mS} / \mathrm{m})$ & $\varepsilon_{\mathrm{i}} / \varepsilon_{0}$ & $n$ \\
\hline \multicolumn{7}{|l|}{ Isotonic media $^{\mathrm{a}}$} \\
\hline $\mathrm{WO}^{-}$ & 5 & $5.8 \pm 0.9$ & $540 \pm 59$ & $541 \pm 66$ & $112 \pm 17$ & 4 \\
\hline $\mathrm{WO}^{-}$ & 10 & $8.8 \pm 1.0$ & $451 \pm 13$ & $839 \pm 64$ & $175 \pm 28$ & 6 \\
\hline $\mathrm{WO}^{-}$ & 20 & $21.1 \pm 4.1$ & $290 \pm 59$ & $631 \pm 56$ & $168 \pm 22$ & 16 \\
\hline $\mathrm{WO}^{-}$ & 50 & $35.3 \pm 4.8$ & $163 \pm 22$ & $609 \pm 40$ & $180 \pm 32$ & 10 \\
\hline $\mathrm{WW}^{-}$ & 5 & $48.0 \pm 4.4$ & $423 \pm 26$ & $733 \pm 139$ & $195 \pm 27$ & 4 \\
\hline $\mathrm{WW}^{-}$ & 10 & $60.7 \pm 3.6$ & $241 \pm 36$ & $448 \pm 45$ & $106 \pm 10$ & 10 \\
\hline $\mathrm{WW}^{-}$ & 20 & $80.1 \pm 9.0$ & $285 \pm 51$ & $725 \pm 17$ & $222 \pm 37$ & 8 \\
\hline $\mathrm{WW}^{-}$ & 50 & $69.1 \pm 3.5$ & $185 \pm 39$ & $528 \pm 76$ & $126 \pm 15$ & 8 \\
\hline \multicolumn{7}{|l|}{ Hypotonic media $^{a}$} \\
\hline $\mathrm{WO}^{-}$ & 20 & $33.0 \pm 6.0$ & $203 \pm 21$ & $470 \pm 33$ & $136 \pm 24$ & 12 \\
\hline $\mathrm{WW}^{-}$ & 50 & $78.0 \pm 10.7$ & $268 \pm 27$ & $496 \pm 63$ & $189 \pm 33$ & 10 \\
\hline $\mathrm{DPA}^{-}$ & 10 & $24.6 \pm 2.5$ & $20.2 \pm 2.3$ & $370 \pm 30$ & $153 \pm 21$ & 9 \\
\hline
\end{tabular}

${ }^{\text {a }}$ Iso- and hypotonic media of osmolalities of 300 and $100 \mathrm{mOsm}$, respectively, were used

Table 5 Membrane capacitance increments $\left(\Delta C_{\mathrm{LI}}\right)$, translocation rate constants $\left(k_{\mathrm{i}}\right)$ of mobile charges and cytosolic properties of Jurkat lymphocytes derived from the ROT spectra in the presence of various concentrations of lipophilic anions under hypotonic conditions

\begin{tabular}{lcclcrc}
\hline Lipophilic anion & Concentration $(\mu \mathrm{M})$ & $\Delta C_{\mathrm{LI}}\left(\mathrm{mF} / \mathrm{m}^{2}\right)$ & $k_{\mathrm{i}}\left[1 /\left(\mathrm{s} * 10^{3}\right)\right]$ & $\sigma_{\mathrm{i}}(\mathrm{mS} / \mathrm{m})$ & $\varepsilon_{\mathrm{i}} / \varepsilon_{0}$ & $n$ \\
\hline $\mathrm{WO}^{-}$ & 20 & $19.6 \pm 1.2$ & $178 \pm 11$ & $421 \pm 15$ & $80 \pm 11$ & 13 \\
$\mathrm{WO}^{-}$ & 50 & $32.6 \pm 4.3$ & $105 \pm 5$ & $456 \pm 18$ & $109 \pm 20$ & 6 \\
$\mathrm{WO}^{-}$ & 100 & $25.2 \pm 2.1$ & $90 \pm 5.2$ & $440 \pm 38$ & $76 \pm 4$ & 6 \\
$\mathrm{WW}^{-}$ & 10 & $9.1 \pm 0.7$ & $348 \pm 55$ & $468 \pm 35$ & $80 \pm 11$ & 8 \\
$\mathrm{WW}^{-}$ & 20 & $9.3 \pm 0.6$ & $391 \pm 43$ & $395 \pm 30$ & $86 \pm 9$ & 9 \\
$\mathrm{WN}^{-}$ & 20 & $4.2 \pm 0.5$ & $130 \pm 28$ & $543 \pm 22$ & $94 \pm 6$ & 6 \\
$\mathrm{WS}^{-}$ & 5 & $\sim 0$ & n.d. & $338 \pm 33$ & $96 \pm 11$ & 11 \\
$\mathrm{DPA}^{-}$ & 5 & $11.0 \pm 0.6$ & $29.9 \pm 1.7$ & $341 \pm 33$ & $96 \pm 18$ & 9 \\
$\mathrm{DPA}^{-}$ & 10 & $8.8 \pm 0.4$ & $34.5 \pm 3.2$ & $386 \pm 46$ & $120 \pm 10$ & 10 \\
\hline
\end{tabular}

charge displacement across the membrane, which in turn gives rise to an apparent increase of membrane capacitance.

In agreement with our data, bell-shaped relationships between membrane capacitance and potential have been reported for cardiac myocytes doped with $\mathrm{DPA}^{-}$(Lu et al., 1995), for outer hair cells (OHCs) treated with $\mathrm{TPB}^{-}(\mathrm{Wu}$ \& Santos-Sacchi, 1998) and other systems (Fernandez et al., 1983). Likewise, the relaxation of gating charges in various channel proteins also gives rise to a bell-shaped dependence of membrane capacitance on membrane voltage, as found in various muscle, excitable and sensory cells (Armstrong \& Bezanilla, 1973; Stefani et al., 1994; Navarrete \& Santos-Sacchi, 2006; Belyantseva et al., 2000; Frolenkov et al., 2000; Kilic \& Lindau, 2001).

In the present study, $V_{\text {mid }}$ was found to depend on the cell type, structure and concentration of lipophilic anions (Tables 1 and 2). Except for the lowest $\mathrm{WO}^{-}$concentration (5 $\mu \mathrm{M})$, HEK cells exhibited negative $V_{\text {mid }}$ values ranging between $\sim-30$ and $-90 \mathrm{mV}$ (Table 1 ). In oocyte membrane (Table 2), $V_{\text {mid }}$ values were even more negative (from -60 to $-120 \mathrm{mV}$, except for $\mathrm{WS}^{-}$) compared to the corresponding data on HEK cells. In accordance with our results, $\mathrm{Lu}$ et al. (1995) and Oberhauser \& Fernandez (1995) found for $\mathrm{DPA}^{-}$a $V_{\text {mid }}$ of $-60 \mathrm{mV}$ in Xenopus oocytes, which was more negative than in human cardiac and mouse mast cells $\left(V_{\text {mid }} \approx-10 \mathrm{~m} V\right.$ ). For comparison, the $V_{\text {mid }}$ values in OHCs treated with various $\mathrm{TPB}^{-}$concentrations varied between -15 and $-46 \mathrm{~m} V$ (Oberhauser \& Fernandez, 1995).

For most lipophilic anions tested here, $V_{\text {mid }}$ shifted to hyperpolarized (i.e., negative) levels in a concentrationdependent manner (Fig. 3). A similar dependence of $V_{\text {mid }}$ on concentration was found in OHCs treated with very low concentrations of $\mathrm{TPB}^{-}(0.2-1 \mu \mathrm{M})$ (Oberhauser \& Fernandez, 1995). In the present study, $V_{\text {mid }}$ changed only little (from -59.5 to $-61.4 \mathrm{mV}$ ) upon increasing the concentration of $\mathrm{TPB}^{-}$from 5 to $50 \mu \mathrm{M}$ (Table 1).

Negative $V_{\text {mid }}$ values imply that lipophilic anions tend to be excluded from the outer membrane leaflet. The poorer affinity for the outer membrane leaflet seems to be a 
Fig. 6 The apparent capacitance increment $\left(\Delta C_{\mathrm{LI}}\right)$ (a), translocation rate constant $\left(k_{\mathrm{i}}\right)(\mathbf{b})$, midpoint potential $\left(V_{\text {mid }}\right)(\mathbf{c})$ of the induced capacitance and slope parameter $(\alpha)$ (d) for the lipophilic anion $\mathrm{WW}^{-}$adsorbed to the plasma membrane of HEK cells as functions of $\mathrm{WW}^{-}$ concentration in bath medium. The data were obtained by electrorotation $\left(\Delta C_{\mathrm{LI}}\right.$ and $k_{\mathrm{i}}$, open symbols) and voltage clamp $\left(\Delta C_{\mathrm{LI}}, V_{\mathrm{mid}}\right.$ and $\alpha,($ filled symbols). Note that the two independent techniques yielded comparable $\Delta C_{\mathrm{LI}}$ values (a)
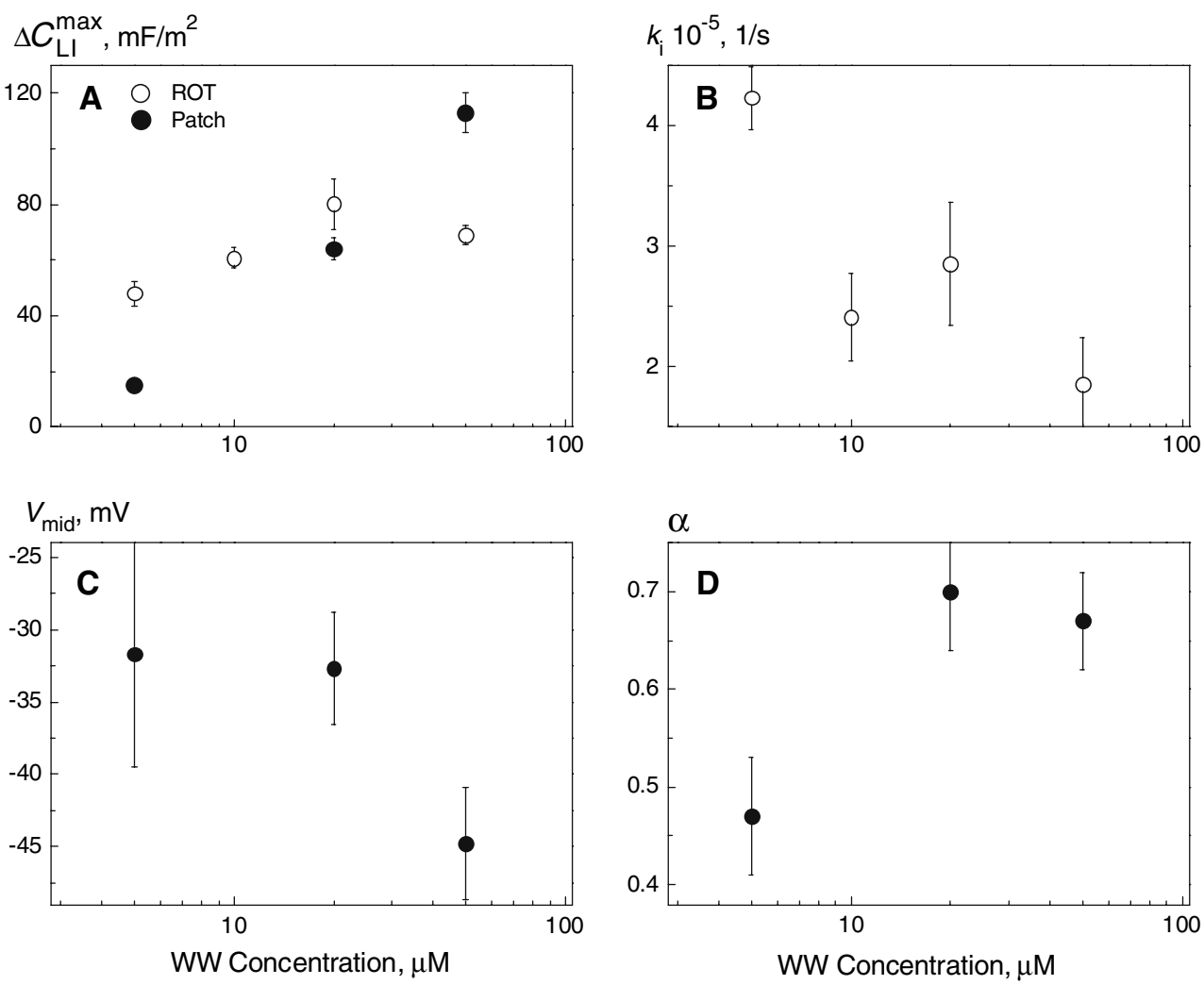

common feature of lipophilic anions. As pointed out elsewhere (Lu et al., 1995), the exclusion of anionic adsorbates from the outer membrane leaflet may be due to the asymmetric distribution of charged phospholipids between the leaflets, typical for biological membranes (e.g., by glycosylation of extracellular lipids). Interestingly, the asymmetry seemed to be enhanced with increasing concentration of the adsorbed lipophilic ions. This effect was quite strong in the case of $\mathrm{WO}^{-}$and, to a lesser extent, in the other investigated lipophilic ions (see Table 1).

\section{Depth of the Adsorption Plane}

The dimensionless slope parameter $\alpha$, determined by fitting the Boltzmann equation to the bell-shaped $\Delta C_{\mathrm{LI}}-V_{\mathrm{H}}$ relations, represents the fraction of the transmembrane potential through which the adsorbed lipophilic anion translocates (Läuger et al., 1981). This parameter can therefore be viewed as a measure of the depth of the adsorption plane of lipophilic anions within the membrane. A value of $\alpha$ close to unity indicates that the adsorbed ions reside in the leaflet of the polar head groups of the lipid molecules, whereas small $\alpha$ values (e.g., $\sim 0.2$ ) are indicative of the preferential adsorption in the region of hydrocarbon tails (Malkia, Liljeroth \& Kontturi, 2003).
At the extracellular concentration of $5 \mu \mathrm{m}$, the slope parameter $\alpha$ measured in HEK cells varied only slightly among the tested lipophilic anions. The lowest $\alpha$ of 0.45 was obtained for $\mathrm{WO}^{-}$and the highest, 0.56, was for $\mathrm{B}\left(\mathrm{CF}_{3}\right)_{4}^{-}$(Table 1). Upon increasing 10-fold (i.e., to $50 \mu \mathrm{M})$ the concentration of large organic anions, including $\mathrm{DPA}^{-}, \mathrm{TFB}^{-}$and $\mathrm{B}\left(\mathrm{CF}_{3}\right)_{4}^{-}$, the strong increase of $N_{\mathrm{t}}$ was also accompanied by a decline of $\alpha$ (e.g., from 0.51 to 0.41 for $\mathrm{DPA}^{-}$and from 0.52 to 0.36 for $\mathrm{TPB}^{-}$). This finding can be explained by the assumption that the adsorption plane of large organic anions moved slightly toward the center of the membrane as the concentration of adsorbed anions increases. By contrast, $\alpha$ remained nearly unchanged in the case of $\mathrm{WO}^{-}(\alpha=0.40-0.45)$ but increased significantly from 0.47 to 0.67 in the case of $\mathrm{WW}^{-}$. The latter finding suggests that the adsorption depth of $\mathrm{WW}^{-}$ decreases as its concentration in the cell membrane increases.

Interestingly, the range of $\alpha$ between 0.4 and 0.7 obtained here for various lipophilic anions adsorbed to the HEK cell membrane agrees well with the values of 0.57 , 0.63 and 0.76 reported for $\mathrm{DPA}^{-}$in mouse mast cells, squid axon and guinea pig cardiac myocytes, respectively (Oberhauser \& Fernandez, 1995; Lu et al., 1995; Fernandez et al., 1983). Somewhat higher $\alpha$ values of $0.75-0.92$ have been obtained for $\mathrm{TPB}^{-}$from voltage-clamp experiments on artificial membranes made from bacterial phospholipids 
(Andersen \& Fuchs, 1975). Charge-pulse experiments on lecithin membranes have also yielded larger $\alpha$ values (0.85-0.99) for both $\mathrm{DPA}^{-}$and $\mathrm{TPB}^{-}$(Benz et al., 1976) than in the present study. Our finding that a range of structurally dissimilar anions exhibited quite similar $\alpha$ values agrees with the observation that both area and depth of the adsorption sites of $\mathrm{DPA}^{-}, \mathrm{TPB}^{-}$and pentachlorophenolate in phospholipid membrane (evaluated from the adsorption isotherms) are independent of the molecular structure of lipophilic anions (Smejtek \& Wang, 1990).

\section{Transmembrane Mobility of Lipophilic Anions}

As evident from Tables 4 and 5, the lipophilic anions tested here differed markedly in their translocation rate constants $\left(k_{\mathrm{i}}\right)$. In both cell types studied by ROT, the $\mathrm{W}(\mathrm{CO})_{5}$ derivatives (e.g., $\mathrm{WW}^{-}$and $\mathrm{WO}^{-}$) exhibited the highest $k_{\mathrm{i}}$ values, ranging between $\sim 10^{5} \mathrm{~s}^{-1}$ and $5.4 \times 10^{5} \mathrm{~s}^{-1}$. The translocation rate constant of $\mathrm{DPA}^{-}\left(\sim 2\right.$ to $\left.3.5 \times 10^{4} \mathrm{~s}^{-1}\right)$ was lower by a factor of about three to five than the corresponding data of $\mathrm{W}(\mathrm{CO})_{5}$ derivatives. The $k_{\mathrm{i}}$ values obtained for $\mathrm{WW}^{-}$and $\mathrm{DPA}^{-}$in HEK and Jurkat cells are in good agreement with the literature. Thus, $\mathrm{WW}^{-}$has been found to translocate across the plasma membrane of mouse myeloma cells with a $k_{\mathrm{i}}$ of 2 to $6 \times 10^{5} \mathrm{~s}^{-1}$ (Kürschner et al., 1998). The $k_{\mathrm{i}}$ values of $\mathrm{DPA}^{-}$reported here are also of the same order of magnitude as published in the literature for DPA ${ }^{-}$-doped nerve cells $\left(\sim 10^{4} \mathrm{~s}^{-1}\right)$ (Benz \& Nonner, 1981), for $\mathrm{DPA}^{-}$-treated human erythrocytes $\left(\sim 3 \times 10^{4} \mathrm{~s}^{-1}\right)$ (Sukhorukov \& Zimmermann, 1996) and for $\mathrm{DPA}^{-}$-doped planar lipid bilayer membranes $\left(\sim 3 \times 10^{4} \mathrm{~s}^{-1}\right)$ (Dilger \& Benz, 1985).

Analysis of the $k_{\mathrm{i}}$ data in Table 4 and Figure 6 also reveals that with increasing aqueous concentration of lipophilic anions an increase of the capacitance increment, $\Delta C_{\mathrm{LI}}$ (and thus of the concentration of the adsorbed anions, $N_{\mathrm{t}}$ ), was accompanied by a gradual decrease in translocation rate constants, $k_{\mathrm{i}}$. The nonlinear relationship between $k_{\mathrm{i}}$ and $N_{\mathrm{t}}$ may be caused by the generation of boundary potentials as well as by the onset of the discrete charge effect (Andersen et al., 1978; Wang \& Bruner, 1978). The slower translocation can also result from a decrease in the membrane dipole potential due to the screening of its positive end by the adsorbed lipophilic anions, as proposed elsewhere (Clarke \& Lüpfert, 1999).

Among other parameters discussed above (i.e., $\Delta C_{\mathrm{m}}$, $V_{\text {mid }}$ and $\alpha$ ), the translocation rate constant $k_{\mathrm{i}}$ appears to be the one that responds most sensitively to the molecular structure and particularly to the atomic constitution of the outer molecular shell of lipophilic anions. Thus, various derivatives of tungsten pentacarbonyl $\mathrm{W}(\mathrm{CO})_{5}$ (containing five to 10 oxygen atoms in the outer shell) were found to exhibit the highest translocation rates, $k_{\mathrm{i}} \approx$ of $10^{5}-10^{6} \mathrm{~s}^{-}$ ${ }^{1}$, reported so far (Tables 4 and 5) (Kürschner et al., 1998). Furthermore, DPA ${ }^{-}$(although structurally very different from $\mathrm{W}[\mathrm{CO}]_{5}$ derivatives) also contains a large number of oxygen atoms in the outer molecular shell and is capable of translocating rather fast (with $k_{\mathrm{i}}$ of some $10^{4} \mathrm{~s}^{-1}$ ) across both cellular and artificial lipid membranes (Sukhorukov \& Zimmermann, 1996; Benz \& Nonner, 1981).

As already mentioned, the ROT technique is only useful for the detection of relatively fast mobile charges (with $k_{\mathrm{i}}>\sim 10^{3} \mathrm{~s}^{-1}$ ), giving rise to a membrane dispersion in the kilohertz to megahertz frequency range. The finding that the large organic anions $\mathrm{TPB}^{-}$and $\mathrm{B}\left(\mathrm{CF}_{3}\right)_{4}^{-}$induced a strong increase of membrane capacitance detectable by voltage clamp (Tables 1 and 2) but not by electrorotation suggests that these anions (both lacking oxygen atoms) translocate across cell membranes much slower than $\mathrm{DPA}^{-}$ and $\mathrm{W}(\mathrm{CO})_{5}$ derivatives. In fact, the translocation rate constant of $\mathrm{TPB}^{-}\left(k_{\mathrm{i}}=1.3-9 \mathrm{~s}^{-1}\right)$ in artificial lipid membranes is up to two orders of magnitude lower than that of $\operatorname{DPA}^{-}\left(k_{\mathrm{i}}=33-987 \mathrm{~s}^{-1}\right)$ (Benz et al., 1976). Based on the literature and the data of Tables 4 and 5 , the transmembrane mobility of lipophilic anions tested in the present study can be arranged in the following descending order: $\mathrm{WW}^{-}>\mathrm{WO}^{-} \approx \mathrm{WN}^{-}>\mathrm{DPA}^{-}>>\left(\mathrm{TPB}^{-}\right.$, $\left.\mathrm{B}\left[\mathrm{CF}_{3}\right]_{4}^{-}\right)$.

The above considerations lead to the conclusion that the presence of oxygen atoms in the outer molecular shell is an important factor for the fast translocation ability of lipophilic anions. The reason for the fast transmembrane movement of $\mathrm{W}(\mathrm{CO})_{5}$ derivatives and $\mathrm{DPA}^{-}$can be attributed to greater negative charge delocalization in these molecules (due to the strong electronegativity of oxygen), which in turn can result in a weaker electrostatic interaction of these anions with the surrounding membrane molecules.

\section{Concluding Remarks}

In the present study several new lipophilic anions have been characterized by analyzing their adsorption and transport properties in cell membranes by means of the electrorotation and patch-clamp techniques. Restricted to the kilohertz to megahertz frequency range, the ROT technique was capable of detecting only lipophilic anions with relatively high translocation rates, such as $\mathrm{DPA}^{-}$and most anionic derivatives of $\mathrm{W}(\mathrm{CO})_{5}$ studied here and previously (Kürschner et al., 1998; Sukhorukov et al., 2001a). Although not resolved in ROT spectra, slower mobile charges, such as those introduced by $\mathrm{TPB}^{-}$and $\mathrm{B}\left(\mathrm{CF}_{3}\right)_{4}^{-}$, could be readily detected by means of capacitance recording in patch-clamped cells. Besides this, patch- 
clamp measurements of the voltage-dependent membrane capacitance yielded information about the preferential location of the adsorbed lipophilic anions within the membrane as well as about their asymmetric distribution between the inner and outer membrane leaflets. Taken together, the two independent approaches complemented each other, thus providing deeper insight into the mechanisms of interaction of lipophilic ions with cell membranes.

Acknowledgement We thank M. Porcedda and F. Roder for carrying out preliminary experiments. We also thank U. Zimmermann and R. Benz (both at the University of Würzburg) for critical reading of the manuscript and helpful discussions. This work was supported by grants from the Deutsche Forschungsgemeinschaft to V. L. S. (Zi 99/12) and to W. A. S. and V. L. S. (SCHE209/17).

\section{Appendix}

\section{Effect of Lipophilic Ions on Membrane Capacitance}

Lipophilic ions have been postulated to move across a lipid bilayer membrane in three steps (Ketterer et al., 1971): (1) adsorption from the aqueous phase to the lipid-water interface, (2) translocation over the central barrier in the middle of the membrane and (3) desorption into the aqueous phase. The theory of lipophilic ion transport across lipid bilayers and biological membranes is also given in detail elsewhere (Benz \& Conti, 1981; Fernandez et al., 1983).

In response to a change in membrane potential, the adsorbed lipophilic ions generate capacitive (gating) currents as they move between the two membrane boundaries. The analysis given by Fernandez et al. (1983) leads to the following expression for the apparent capacitance increment $\left(\Delta C_{\mathrm{LI}}\right)$ as a function of the holding membrane potential $\left(V_{\mathrm{H}}\right)$ in the presence of a monovalent lipophilic ion:

$\Delta C_{L I}=\frac{N_{t} \alpha F^{2}}{4 R T} \cosh ^{-2}\left(\frac{\alpha F\left(V_{\mathrm{H}}-V_{\text {mid }}\right)}{2 R T}\right)$

where $N_{\mathrm{t}}\left(\mathrm{mol} / \mathrm{m}^{2}\right)$ is the surface density of the adsorbed lipophilic ions. The slope parameter $\alpha$ represents the fraction of the membrane field through which the lipophilic ions translocate (Läuger et al., 1981). The constants $F, R$ and $T$ have their usual meanings. Equation 1 describes a bell-shaped voltage dependence of $\Delta C_{\mathrm{LI}}$ with a peak value $\Delta C_{\mathrm{LI}}^{\max }=\alpha N_{\mathrm{t}} F^{2} /(4 R T)$ centered at a midpoint voltage $\left(V_{\text {mid }}\right)$. This equation represents the first derivative of the Boltzmann function, $1 /\left\{1+\exp \left[-\alpha F\left(V_{\mathrm{H}}-V_{\mathrm{mid}}\right) / R T\right]\right\}$, for the voltage-dependent distribution of the adsorbed lipophilic ions between the two membrane interfaces (Benz \& Nonner, 1981). To derive the parameters $N_{\mathrm{t}}, \alpha$ and $V_{\text {mid }}$ for the various lipophilic anions studied here, equation 1 was fitted to the experimental $\Delta C_{\mathrm{LI}}$ data measured at various holding potentials $\left(V_{\mathrm{H}}\right)$ in HEK cells and Xenopus oocytes by the patch-clamp and TEVC techniques, respectively.

\section{Electrorotation of Control Cells: The Single-Shell Model}

The ROT spectrum, i.e., the frequency dependence of the rotation speed $\Omega$, is fully determined by the imaginary part of the complex cell polarizability, $\chi^{*}$ (Arnold $\&$ Zimmermann, 1988; Jones, 1995; Zimmermann \& Neil, 1996; Fuhr \& Kuzmin, 1986):

$\Omega=-\frac{0.5 \varepsilon_{e} E^{2}}{\eta} \operatorname{Im}\left(\chi^{*}\right)$

where $E$ is the rotating field strength and $\varepsilon_{\mathrm{e}}$ and $\eta$ are medium permittivity and viscosity, respectively. Given that the cell radius $a$ is much larger than the membrane thickness, a simplified expression for the polarizability $\left(\chi^{*}\right)$ of a spherical single-shelled cell can be derived (Sukhorukov et al., 2001a):

$\chi^{*}=\frac{a C_{m}^{*}\left(\varepsilon_{i}^{*}-\varepsilon_{e}^{*}\right)-\varepsilon_{i}^{*} \varepsilon_{e}^{*}}{a C_{m}^{*}\left(\varepsilon_{i}^{*}+2 \varepsilon_{e}^{*}\right)+2 \varepsilon_{i}^{*} \varepsilon_{e}^{*}}$

where the complex permittivity is defined as $\varepsilon^{*}=\varepsilon-$ $\mathrm{j} \sigma / \omega$, with $\varepsilon$ and $\sigma$ for the real permittivity $(\mathrm{F} / \mathrm{m})$ and conductivity $(\mathrm{S} / \mathrm{m})$ of the medium (subscript "e") or the cytosol (subscript " $\mathrm{i}$ "), with the complex number $\mathrm{j}=(-$ $1)^{1 / 2}$ and the radian field frequency $\omega=2 \pi f$. For control cells, the complex area-specific membrane capacitance is given by $C_{\mathrm{m}}^{*}=C_{\mathrm{m}}-\mathrm{j} G_{\mathrm{m}} / \omega$, where $C_{\mathrm{m}}\left(\mathrm{F} / \mathrm{m}^{2}\right)$ and $G_{\mathrm{m}}(\mathrm{S} /$ $\mathrm{m}^{2}$ ) are the membrane capacitance and conductance per unit area, respectively. In the single-shell model, both $C_{\mathrm{m}}$ and $G_{\mathrm{m}}$ are assumed to be independent of field frequency.

For very low-conductivity solutions $\left(\sigma_{\mathrm{e}}<<\sigma_{\mathrm{i}}\right)$, the single-shell model also predicts the linear dependence of the characteristic frequency of the fastest antifield rotation $\left(f_{\mathrm{c} 1}\right)$ on the external conductivity $\left(\sigma_{\mathrm{e}}\right)$ (Arnold \& Zimmermann, 1988):

$f_{c 1} \cdot a=\frac{\sigma_{e}}{\pi \cdot C_{m}}+\frac{a \cdot G_{m}}{2 \pi \cdot C_{m}}$

The mean plasma membrane parameters $C_{\mathrm{m}}$ and $G_{\mathrm{m}}$ of control cells (i.e., not treated with lipophilic anions) were extracted from studying the variation of the radiusnormalized peak frequency $\left(f_{\mathrm{c} 1}\right)$ with the external conductivity (at $\sigma_{\mathrm{e}}<\sim 7 \mathrm{mS} / \mathrm{m}$ ) by means of the CRF technique (see "Materials and Methods"). To extract the dielectric properties of the cytosol $\left(\sigma_{\mathrm{i}}\right.$ and $\left.\varepsilon_{\mathrm{i}}\right)$, the ROT spectra of control cells were fitted by the single-shell model (equations 2 and 3). For fitting ROT spectra, the value sf $=\varepsilon_{\mathrm{e}} \mathrm{E}^{2} / \eta$ (see equation 2) served as a scaling factor, which accounts for the local field strength and frictional 
force experienced by individual cells. Computations were performed with the Mathematica software, Wolfram Research, Champaign, USA.

\section{Electrorotation of Cells Treated with Lipophilic Anions: The Mobile Charge Model}

The analyses of Ketterer et al. (1971) and Fernandez et al. (1983) also predict a frequency-dependent capacitance of cell membranes doped with lipophilic ions. In previous studies (Sukhorukov et al., 2001a; Sukhorukov \& Zimmermann, 1996), we modified the single-shell dielectric model (equations 2 and 3) in order to account for the single Debye dispersion arising from the relaxation of adsorbed lipophilic ions (mobile charges). In the mobile charge model the expression for the complex membrane capacitance is given by

$C_{\mathrm{m}}^{*}=C_{\mathrm{m}}+\frac{\Delta C_{\mathrm{LI}}}{1+\mathrm{j} \omega \tau_{\mathrm{LI}}}-\frac{j G_{\mathrm{m}}}{\omega}$

where $\Delta C_{\mathrm{LI}}$ is the zero-frequency capacitance increment and $\tau_{\mathrm{LI}}$ is the time constant of the membrane dispersion due to the transmembrane movement of the adsorbed lipophilic ions. The time constant $\tau_{\mathrm{LI}}$ is related to the translocation rate $k_{\mathrm{i}}$ of the adsorbed ions across the membrane as $k_{\mathrm{i}}=$ $\left(2 \tau_{\mathrm{LI}}\right)^{-1}$ (Ketterer et al., 1971; Pickar \& Brown, 1983). Equation 5 implies that at low field frequencies (i.e., $\left.\omega=2 \pi f<<1 / \tau_{\mathrm{LI}}\right)$ the effective membrane capacitance is given by the sum of the geometric capacitance $\left(C_{\mathrm{m}}\right)$ and the capacitance increment due to the relaxation of adsorbed lipophilic ions $\left(\Delta C_{\mathrm{LI}}\right)$. By contrast, at high field frequencies $\left(\omega>>1 / \tau_{\mathrm{mc}}\right)$ the effective membrane capacitance decreases to its geometric value. The membrane dispersion moves toward higher frequencies with increasing $k_{\mathrm{i}}$.

In order to extract the values for $\Delta C_{\mathrm{LI}}$ and $k_{\mathrm{i}}$, the ROT spectra of cells treated with various concentrations of lipophilic anions were fitted by the mobile charge model (combination of equations 2, 3 and 5). It should be noted that the actual membrane voltage is unknown under electrorotation conditions. Therefore the $\Delta C_{\mathrm{LI}}$ value derived from electrorotation spectra can be smaller than the peak capacitance increment, $\Delta C_{\mathrm{LI}}^{\max }=\alpha N_{\mathrm{t}} F^{2} /(4 R T)$ (see above equation 1 ), if the membrane potential diverges significantly from $V_{\text {mid. }}$. In this case electrorotation can underestimate the total amount of the adsorbed lipophilic anions.

\section{References}

Abel EW, Reid JG, Butler IS (1963) Anionic halogenopentacarbonyls of chromium, molybdenum, and tungsten. J Chem Soc 1963:2068-2070
Andersen OS, Fuchs M (1975) Potential-energy barriers to iontransport within lipid bilayers-studies with tetraphenylborate. Biophys J 15:795-830

Andersen OS, Feldberg S, Nakadomari H, Levy S, Mclaughlin S (1978) Electrostatic interactions among hydrophobic ions in lipid bilayer membranes. Biophys J 21:35-70

Armstrong CM, Bezanilla F (1973) Currents related to movement of gating particles of sodium channels. Nature 242:459-461

Arnold WM, Zimmermann U (1988) Electro-rotation-development of a technique for dielectric measurements on individual cells and particles. J Electrost 21:151-191

Arnold WM, Zimmermann U, Heiden W, Ahlers J (1988) The influence of tetraphenylborates (hydrophobic anions) on yeast cell electro-rotation. Biochim Biophys Acta 942:96-106

Asali KJ, El-Khateeb M, Battaineh TT (2003) Novel anionic heterocyclic thiolate complexes of group VIB metal carbonyls: synthesis and reactivity. Syn Reactiv Inorg Metal Org Chem 33:1047-1062

Belyantseva IA, Frolenkov GI, Wade JB, Mammano F, Kachar B (2000) Water permeability of cochlear outer hair cells: characterization and relationship to electromotility. J Neurosci 20:8996-9003

Benz R (1988) Structural requirement for the rapid movement of charged molecules across membranes. Experiments with tetraphenylborate analogues. Biophys J 54:25-33

Benz R, Läuger P, Janko K (1976) Transport kinetics of hydrophobic ions in lipid bilayer membranes - charge-pulse relaxation studies. Biochim Biophys Acta 455:701-720

Benz R, Conti F (1981) Structure of the squid axon membrane as derived from charge-pulse relaxation studies in the presence of absorbed lipophilic ions. J Membr Biol 59:91-104

Benz R, Nonner W (1981) Structure of the axolemma of frog myelinated nerve-relaxation experiments with a lipophilic probe ion. J Membr Biol 59:127-134

Bernhardt D, Henkel G, Willner H, Pawelke G, Bürger H (2001) Synthesis and properties of the tetrakis(trifluoromethyl)borate anion, $\left[\mathrm{B}\left(\mathrm{CF}_{3}\right)_{4}\right]^{-}$: structure determination of $\mathrm{Cs}\left[\mathrm{B}\left(\mathrm{CF}_{3}\right)_{4}\right]$ by single-crystal X-ray diffraction. Chem Eur J 7:4696-4705

Blunck R, Chanda B, Bezanilla F (2005) Nano to micro-fluorescence measurements of electric fields in molecules and genetically specified neurons. J Membr Biol 208:91-102

Chanda B, Asamoah OK, Blunck R, Roux B, Bezanilla F (2005) Gating charge displacement in voltage-gated ion channels involves limited transmembrane movement. Nature 436:852-856

Clarke RJ, Lüpfert C (1999) Influence of anions and cations on the dipole potential of phosphatidylcholine vesicles: a basis for the Hofmeister effect. Biophys J 76:2614-2624

De Wever H, Vereecken K, Stolz A, Verachtert H (1998) Initial transformations in the biodegradation of benzothiazoles by Rhodococcus isolates. Appl Environ Microbiol 64:3270-3274

Dilger JP, Benz R (1985) Optical and electrical properties of thin monoolein lipid bilayers. J Membr Biol 85:181-189

Dilsky S, Schenk WA (2006) Anionic tungsten carbonyl complexes containing dithiocarboxylate, dithiocarbamate, and xanthate ligands. Z Naturforsch [B] 61:570-576

Fernandez JM, Taylor RE, Bezanilla F (1983) Induced capacitance in the squid giant axon-lipophilic ion displacement currents. J Gen Physiol 82:331-346

Flewelling RF, Hubbell WL (1986) Hydrophobic ion interactions with membranes - thermodynamic analysis of tetraphenylphosphonium binding to vesicles. Biophys J 49:531-540

Frolenkov GI, Mammano F, Belyantseva IA, Coling D, Kachar B (2000) Two distinct $\mathrm{Ca}^{2+}$-dependent signaling pathways regulate the motor output of cochlear outer hair cells. J Neurosci 20:5940-5948 
Fuhr G, Kuzmin PI (1986) Behavior of cells in rotating electric fields with account to surface-charges and cell structures. Biophys $\mathbf{J}$ 50:789-795

Jones TB (1995) Electromechanics of particles. New York: Cambridge University Press

Ketterer B, Neumcke B, Läuger P (1971) Transport mechanism of hydrophobic ions through lipid bilayer membranes. J Membr Biol 5:225-245

Kiesel M, Reuss R, Endter J, Zimmermann D, Zimmermann H, Shirakashi R, Bamberg E, Zimmermann U, Sukhorukov VL (2006) Swelling-activated pathways in human T-lymphocytes studied by cell volumetry and electrorotation. Biophys J 90:4720-4729

Kilic G, Lindau M (2001) Voltage-dependent membrane capacitance in rat pituitary nerve terminals due to gating currents. Biophys $\mathbf{J}$ 80:1220-1229

Klodos I (2003) Influence of intramembrane electric charge on $\mathrm{H}, \mathrm{K}-$ ATPase. Ann N Y Acad Sci 986:306-307

Kürschner M, Nielsen K, Andersen C, Sukhorukov VL, Schenk WA, Benz R, Zimmermann U (1998) Interaction of lipophilic ions with the plasma membrane of mammalian cells studies by electrorotation. Biophys J 74:3031-3043

Kürschner M, Nielsen K, von Langen JRG, Schenk WA, Zimmermann U, Sukhorukov VL (2000) Effect of fluorine substitution on the interaction of lipophilic ions with the plasma membrane of mammalian cells. Biophys J 79:1490-1497

Läuger P, Benz R, Stark G, Bamberg E, Jordan PC, Fahr A, Brock W (1981) Relaxation studies of ion transport systems in lipid bilayer membranes. Q Rev Biophys 14:513-598

Lu CC, Kabakov A, Markin VS, Mager S, Frazier GA, Hilgemann DW (1995) Membrane transport mechanisms probed by capacitance measurements with megahertz voltage clamp. Proc Natl Acad Sci USA 92:11220-11224

Malkia A, Liljeroth P, Kontturi K (2003) Membrane activity of ionisable drugs - a task for liquid-liquid electrochemistry? Electrochem Commun 5:473-479

Mukherjee A, Westwell AD, Bradshaw TD, Stevens MFG, Carmichael J, Martin SG (2005) Cytotoxic and antiangiogenic activity of AW464 (NSC 706704), a novel thioredoxin inhibitor: an in vitro study. Br J Cancer 92:350-358

Nagel G, Volk C, Friedrich T, Ulzheimer JC, Bamberg E, Koepsell H (1997) A reevaluation of substrate specificity of the rat cation transporter rOCT1. J Biol Chem 272:31953-31956

Navarrete E, Santos-Sacchi J (2006) On the effect of prestin on the electrical breakdown of cell membranes. Biophys J 90:967-974

Oberhauser AF, Fernandez JM (1995) Hydrophobic ions amplify the capacitive currents used to measure exocytotic fusion. Biophys J $69: 451-459$
Pickar AD, Brown WC (1983) Capacitance of bilayers in the presence of lipophilic ions. Biochim Biophys Acta 733:181-185

Reuss O, Kürschner M, Dilsky S, Horbaschek M, Schenk WA, Zimmermann U, Sukhorukov VL (2002) Interaction of fluorinated lipophilic ions with the plasma membrane of mammalian cells studied by electrorotation and dielectrophoresis. J Electrost 56:419-434

Schamberger J, Clarke RJ (2002) Hydrophobic ion hydration and the magnitude of the dipole potential. Biophys J 82:3081-3088

Singh T, Srivastava VK, Saxena KK, Goel SL, Kumar A (2006) Synthesis of new thiazolylthiazolidinylbenzothiazoles and thiazolylazetidinylbenzothiazoles as potential insecticidal, antifungal, and antibacterial agents. Arch Pharm (Weinheim) 339:466-472

Smejtek P, Wang S (1990) Adsorption to dipalmitoylphosphatidylcholine membranes in gel and fluid state-pentachlorophenolate, dipicrylamine, and tetraphenylborate. Biophys J 58:1285-1294

Stefani E, Toro L, Perozo E, Bezanilla F (1994) Gating of Shaker K ${ }^{+}$ channels: 1. Ionic and gating currents. Biophys J 66:996-1010

Strohbusch F, Marshall DB, Vazquez FA, Cummings AL, Eyring EM (1979) Dissociation kinetics of picric acid and dipicrylamine in methanol-steric effect on a proton-transfer rate. J Chem Soc Faraday Trans 1 75:2137-2142

Sukhorukov VL, Zimmermann U (1996) Electrorotation of erythrocytes treated with dipicrylamine: mobile charges within the membrane show their "signature" in rotational spectra. J Membr Biol 153:161-169

Sukhorukov VL, Kürschner M, Dilsky S, Lisec T, Wagner B, Schenk WA, Benz R, Zimmermann U (2001a) Phloretin-induced changes of lipophilic ion transport across the plasma membrane of mammalian cells. Biophys J 81:1006-1013

Sukhorukov VL, Meedt G, Kürschner M, Zimmermann U (2001b) A single-shell model for biological cells extended to account for the dielectric anisotropy of the plasma membrane. J Electrost 50:191-204

Sukhorukov VL, Reuss R, Zimmermann D, Held C, Müller KJ, Kiesel M, Gessner P, Steinbach A, Schenk WA, Bamberg E, Zimmermann U (2005) Surviving high-intensity field pulses: strategies for improving robustness and performance of electrotransfection and electrofusion. J Membr Biol 206:187-201

Wang CC, Bruner LJ (1978) Evidence for a discrete charge effect within lipid bilayer membranes. Biophys J 24:749-764

Wu M, Santos-Sacchi J (1998) Effects of lipophilic ions on outer hair cell membrane capacitance and motility. J Membr Biol 166:111-118

Zimmermann U, Neil GA (1996) Electromanipulation of cells. Boca Raton, FL: CRC Press 